\title{
INCOMPATIBILIDADE POR TRANSLOCAÇÃO EM ENXERTOS DE CLONES DE COPA DE SERINGUEIRA E O CLONE DE PAINEL IPA 1. TESTES DA HIPÓTESE DO EFEITO DO POTENCIAL CIANOGÊNICO DOS CLONES DE COPA
}

\section{LARISSA ALEXANDRA CARDOSO MORAES}

Engenheiro Agrônomo

Orientador: Prof. Dr. PAULO ROBERTO DE CAMARGO E CASTRO

\begin{abstract}
Dissertação apresentada à Escola Superior de Agricultura "Luiz de Queiroz", da Universidade de São Paulo, para obtenção do título de Mestre em Ciências, Área de Concentração: Fisiologia e Bioquímica de Plantas.
\end{abstract}

P I R A C I C A B A

Estado de São Paulo - Brasil

Agosto - 2000 
Dados Internacionais de Catalogação na Publicação (CIP)

DIVISÃO DE BIBLIOTECA E DOCUMENTAÇÃO - Campus "Luiz de Queiroz"/USP

Moraes, Larissa Alexandra Cardoso

Incompatibilidade por translocação em enxertos de clones de copa de seringueira e o clone de painel ipa 1. testes da hipótese do efeito do potencial cianogênico dos clones de copa / Larissa Alexandra Cardoso Moraes. - Piracicaba, 2000.

51 p. : il. 2000.

Dissertação (mestrado) - - Escola Superior de Agricultura Luiz de Queiroz, Bibliografia.

1. Seringueira 2. Enxertia de copa 3. Incompatibilidade por translocação 3. Cianogênese 4. Glicosídio cianogênico 5. $\beta$-glicosidase I. Título

$$
\operatorname{CDD} 633.895
$$




\section{AGRADECIMENTOS}

A Embrapa, através do Centro de Pesquisa Agroflorestal da Amazônia Ocidental (CPAA), pela oportunidade de realização do curso;

A Escola Superior de Agricultura "Luiz de Queiroz"-USP pela oportunidade oferecida;

Ao meu pai, Vicente Haroldo de Figueiredo Moraes, pesquisador do CPAA, pelas sugestões, apoio, amizade e incentivo;

Ao Prof. Dr. Paulo Roberto de Camargo e Castro pelo apoio e confiança demonstrada;

A todos os demais professores do Curso de Fisiologia e Bioquímica de Plantas pelos conhecimentos transmitidos;

Ao Adônis pelo carinho, dedicação, paciência e auxílio nas análises estatísticas;

Ao funcionário do Laboratório de Fisiologia Vegetal do CPAA, Sérgio de Araújo Silva, pelo auxílio na realização das análises de laboratório;

A Telma e Adriana pelo apoio e amizade descompromissada;

A Rosário e Ayres pela solidariedade e amizade;

Aos amigos de Curso Fábio, Daniela, Juliana, Adriano e Lucimara pela amizade e feliz convivência;

A todos os demais que direta ou indiretamente contribuíram para a realização deste trabalho. 


\section{SUMÁRIO}

Página

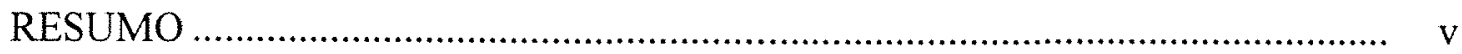

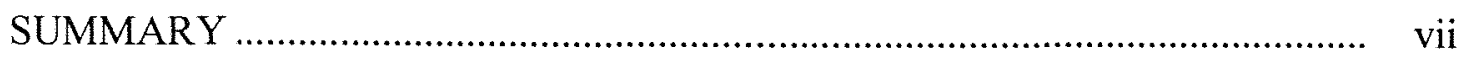

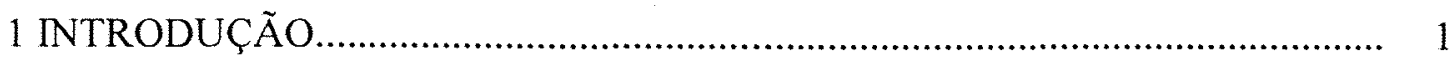

2 REVISÃO DE LITERATURA …............................................................

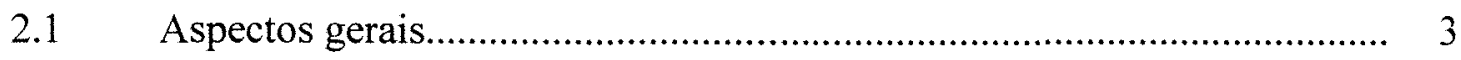

2.2 Processos de incompatibilidade em enxertia.............................................. 4

$2.3 \quad$ Cianogênese .............................................................................. 7

2.3.1 Processos de liberação e metabolismo do HCN ………............................. 8

2.3.2 Enzimas envolvidas nos processos de liberação e metabolismo do HCN

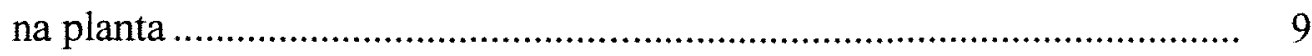

2.3.3 Função da cianogênese e dos compostos cianogênicos na planta.............. 12

2.3.4 Transporte dos compostos cianogênicos no interior da planta................... 13

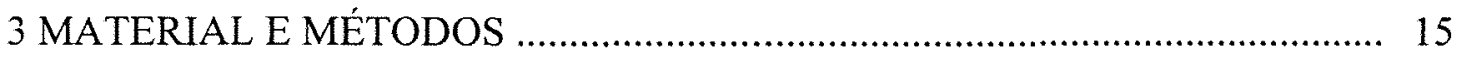

3.1 Localização ............................................................................. 15

3.2 Resposta à aplicação de $\mathrm{KCN}$, em dose única ....................................... 15

3.3 Resposta à aplicação contínua de $\mathrm{KCN}$................................................ 16

3.4 Resposta à aplicação de linamarina...................................................... 16

3.5 Ação do cianeto na coagulação do látex "in vitro" ................................... 16

3.6 Concentração de $\mathrm{HCN}$ livre nos caules submetidos a diferentes tempos de exposição à solução de linamarina ......................................................... 17

3.6.1 Preparo da amostra ....................................................................... 17

3.6.2 Determinação de HCN livre ............................................................. 18

3.7 Atividade da $\beta$-cianoalaninasintase $(\beta$-CAS) ........................................ 18 
3.8 Atividade da $\beta$-glicosidase (linamarase) ........................................... 19

3.8.1 Extração. semipurificação e concentração da enzima................................. 19

3.8.2 Determinação da atividade da enzima..................................................... 20

3.9 Enxertia de clones de copa de baixo potencial cianogênico, no clone

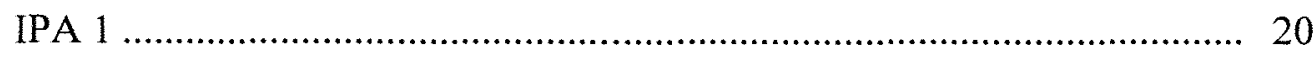

3.10 Atividade da $\beta$-diglicosidase (linustatinase) .......................................... 21

3.10.1 Extração, semipurificação e concentração da enzima................................. 21

3.10.2 Determinação da atividade da enzima.................................................. 21

3.11 Potencial cianogênico ( $\mathrm{HCN}-\mathrm{p})$ de clones de copa de seringueira ............ 21

3.11.1 Extração da linamarase das folhas de seringueira.................................... 22

3.11.1.1 Determinação da atividade da linamarase ................................................ 23

3.11.2 Determinação do HCN-p em folhas jovens e maduras ............................. 24

3.11.2.1 Preparo da amostra ............................................................................. 24

3.11.2.2 Determinação do HCN-p.................................................................... 24

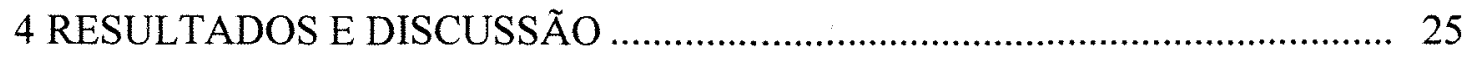

4.1 Resposta à aplicação de $\mathrm{KCN}$, em dose única ....................................... 25

4.2 Resposta à aplicação contínua de $\mathrm{KCN}$................................................ 27

4.3 Resposta à aplicação de linamarina........................................................... 27

4.3.1 Marcha de absorção das soluções ........................................................... 27

4.3.2 Efeito sobre o escoamento do látex e indução de necrose .......................... 28

4.4 Ação do cianeto na coagulação do látex "in vitro" ...................................... 30

4.5 Concentração de $\mathrm{HCN}$ livre nos caules submetidos a diferentes tempos de exposição à solução de linamarina ........................................................ 31

4.6 Atividade da $\beta$-cianoalaninasintas ( $\beta$-CAS) …...................................... 32

4.7 Atividade da $\beta$-glicosidase (linamarase) ................................................ 33

4.8 Enxertia de clones de copa de baixo potencial cianogênico, no clone

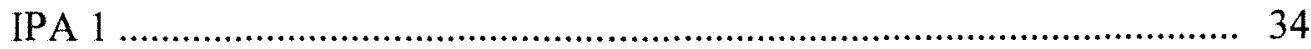

$4.9 \quad$ Atividade da $\beta$-diglicosidase (linustatinase) ....................................... 37

4.10 Potencial cianogênico ( $\mathrm{HCN}-\mathrm{p})$ de clones de copa de seringueira ............. 38 
5 CONCLUSÕES.

REFERÊNCIAS BIBLIOGRÁFICAS ............................................................... 44 


\title{
INCOMPATIBILIDADE POR TRANSLOCAÇÃO EM ENXERTOS DE CLONES DE COPA DE SERINGUEIRA E O CLONE DE PAINEL IPA 1. TESTES DA HIPÓTESE DO EFEITO DO POTENCIAL CIANOGÊNICO DOS CLONES DE COPA
}

\author{
Autor: Larissa Alexandra Cardoso Moraes \\ Orientador: Prof. Dr. Paulo Roberto de Camargo e Castro
}

\section{RESUMO}

O clone IPA 1, de seringueira (Hevea brasiliensis), apresenta incompatibilidade por translocação, em enxertos de copa com vários clones de outras espécies de Hevea. $\mathrm{O}$ primeiro sintoma da incompatibilidade é a ausência do escoamento do látex no caule do IPA 1, abaixo da união do enxerto, devida à coagulação do látex nos laticíferos. Seguese a necrose da casca do IPA 1, em enxertos com três a quatro lançamentos foliares e a morte do enxerto após o anelamento completo da casca.

A aplicação de soluções de $\mathrm{KCN}$ no caule provocou rápida coagulação do látex, com concentrações muito baixas de $\mathrm{KCN}$, no IPA 1, com concentrações mais altas no clone Fx 4098 e não teve efeito no Fx 3864, exceto leve redução de escoamento, com a dose mais alta. Os tratamentos com $\mathrm{KCN}$ causaram necrose apenas próximo ao local das aplicações. Com soluções de linamarina houve translocação de maior quantidade desse glicosídeo cianogênico, a julgar pela necrose em maior extensão ao longo do caule, também precedida pela coagulação do látex, mostrando-se o IPA 1, novamente, sensível às concentrações mais baixas de linamarina, com doses mais altas provocando os mesmos efeitos no Fx 4098 e sem ocorrência de efeitos no Fx 3864.

A extrema sensibilidade do IPA 1 corresponde a atividade muito baixa na casca do caule de desintoxicação do cianeto pela $\beta$-cianoalaninasintase ( $\beta$-CAS), que corresponde, nesse clone, ao mesmo nível encontrado em espécies não cianogênicas, tendo o Fx 3864 apresentado atividade muito alta e o Fx 4098, um pouco menor. A maior atividade de $\beta$-glicosidase encontrada no IPA 1 , associada à baixa atividade de $\beta$ - 
CAS. provoca acúmulo de $\mathrm{HCN}$ livre na casca do caule desse clone, responsável pelos sintomas observados nos tratamentos com linamarina.

Os clones de baixo potencial cianogênico ( $\mathrm{HCN}-\mathrm{p}$ ) mostraram-se compativeis, bem como os que possuem HCN-p alto nas folhas jovens, sem redução nas folhas maduras. Os clones de HCN-p alto, com sensível redução nas folhas maduras, mostraram-se incompatíveis. Esse conjunto de evidências é coerente com a hipótese de que a incompatibilidade é causada pela translocação de glicosídeo cianogênico das folhas dos clones enxertados, para o caule do IPA 1. A forma natural de transporte é o diglicosídeo linustatina, encontrado em exsudado de nectários da base do pecíolo. A atividade de $\beta$-diglicosidase, mais alta no caule do IPA 1 , é também uma evidência a favor da hipótese da translocação. Como a linustatina é transportada em baixa concentração no floema e a atividade encontrada de $\beta$-diglicosidase foi muito mais baixa que a de $\beta$-glicosidase, explica-se o intervalo mais longo para o aparecimento da necrose, que com os tratamentos com linamarina.

A semelhança dos sintomas descritos com os da síndrome do secamento do painel de sangria sugere o envolvimento da cianogênese na sua evolução. 


\title{
TRANSLOCATION INCOMPATIBILITY OF CROWN CLONES OF Hevea spp., BUDDED ONTO IPA 1 (H. brasiliensis). TESTS OF THE HYPOTHESIS OF THE EFFECT OF THE CYANOGENIC POTENTIAL OF THE CROWN CLONES
}

\author{
Author: Larissa Alexandra Cardoso Moraes \\ Adviser: Paulo Roberto de Camargo e Castro
}

\section{SUMMARY}

The clone IPA 1 of rubber tree (Hevea brasiliensis) presents translocation graft incompatibility with crown clones of other Hevea species. The first symptom of incompatibility is the blockage of latex flow on the IPA 1 stem below the graft union, due to latex coagulation. This is followed by bark necrosis of IPA 1, when the budded crowns reach three to four leaf whorls.

Treatments of stems with $\mathrm{KCN}$ solutions caused rapid latex coagulation, with very low concentrations, in IPA 1 , the same effect being observed with higher concentrations, in Fx 4098, but only a slight reduction of latex flow, with the highest concentration, in Fx $3864 . \mathrm{KCN}$ treatments caused necrosis only close to the site of application. There was a higher amount of translocation with linamarin solutions, as judged from the necrosis extending longer along the stem, preceded by latex coagulation, again with the lower concentrations of linamarin in IPA 1, with higher concentrations in Fx 4098, without any effect in Fx 3864.

The extreme susceptibility of IPA 1 is matched by a very low cyanide detoxifying $\beta$-cyanoalanine synthase activity in the stem bark of IPA 1 , which is of the same order of non-cyanogenic species, whereas the Fx 3864 displayed a very high intensity of $\beta$-CAS activity and the Fx 4098 a somewhat lower activity. The higher $\beta$ glycosidase activity found in IPA 1 , together with the low $\beta$-CAS activity, led to the accumulation of free $\mathrm{HCN}$ in the stem bark, which accounts for the observed symptoms of linamarin application. 
Clones with low cyanogenic potential ( $\mathrm{HCN}-\mathrm{p})$ in young leaves were found to be compatible, as well as clones with high $\mathrm{HCN}-\mathrm{p}$, but maintaining a high $\mathrm{HCN}-\mathrm{p}$ in mature leaves. Clones with high $\mathrm{HCN}$-p in young leaves, but with significant reduction in mature leaves, were incompatible. This set of evidences support the hypothesis that the incompatibility is due to the translocation of cyanogenic glycosides from the leaves of budded crowns to the stem of IPA 1 . The diglycoside linustatin, found in the exsudate of nectaries at the base of the petioles, is the natural form of transport in Hevea. The high diglycosidase activity found in the stem of IPA 1 is an additional support for the translocation hypothesis. As linustatin is transported in low concentration in the phloem and the $\beta$-diglycosidase activity was found to be much lower than the $\beta$-glycosidase activity, this explains why the lag for the outcome of necrosis in the incompatible combination is longer than with the application of linamarin.

The symptoms described are similar to those found in the tapping panel dryness syndrome, suggesting a link between cyanogenesis and the development of bark dryness. 


\section{INTRODUÇÃO}

A enxertia de copa com clones de seringueira (Hevea spp.) resistentes ao maldas-folhas, causado pelo fungo Microcyclus ulei, vem sendo objeto de pesquisa há vários anos e tem sido utilizada em plantios comerciais, em pequena escala, na Amazônia e no litoral sul da Bahia.

Em 136 combinações copa/painel já estudadas na Amazônia e no litoral sul da Bahia, nunca houve registro de quebra do caule no tecido de união do enxerto de copa. Com uma única exceção para a combinação do clone Fx 516, como copa de PR 107, que teve quebra do caule no tecido de união, causada por ventos fortes (Dunham et al., 1982). Em outros casos de quebra do caule pelo vento, verifica-se que ocorrem acima ou abaixo do tecido de união, o que demonstra ausência de incompatibilidade localizada, do tipo descrito por Mosse (1962) e Hartmann et al. (1990), mesmo em se tratando de combinações entre espécies, como de Hevea pauciflora ou H. benthamiana, sobre troncos de H. brasiliensis (Pinheiro et al., 1988).

Essa ocorrência rara de incompatibilidade localizada, mesmo nos enxertos entre diferentes espécies de Hevea, corresponde a alta taxa de introgressão de genes entre espécies encontradas em ambiente natural (Baldwin Jr., 1947 e Seibert, 1947) e a alta compatibilidade dos cruzamentos interespecíficos dos programas de melhoramento genético.

A incompatibilidade por translocação, tal como definida por Mosse (1962) e Hartmann et al. (1990), não havia ainda sido registrada em enxertos da mesma espécie, ou entre espécies de Hevea.

Em ensaio de teste de clones de copa, utilizando-se plantas jovens, tal tipo de incompatibilidade foi constatada, recentemente, em combinações cujo clone de painel foi o IPA 1 e os de copa, os provenientes de $H$. pauciflora e $H$. guianensis var. 
marginata. Vale ressaltar que copas de Hgm 3 (H. guianensis var. marginata) e Fx 985 (H. brasiliensis) mostraram-se compatíveis nas combinações com o mesmo painel (Moraes \& Moraes, 1996).

Em ensaio anterior, a copa de IAN 6158 (H. brasiliensis $\times$ H. benthamiana) também mostrou-se compatível, tendo sido, porém, a única copa utilizada sobre o IPA 1 (Moraes \& Moraes, 1995). Nessa fase não foi, portanto, evidenciada a incompatibilidade por translocação.

Após a constatação dessa anomalia, foi testada, sobre o IPA 1, a enxertia com vários clones híbridos de $H$. pauciflora com $H$. rigidiflora e $H$. guianensis var. marginata e dois clones de $H$. nitida.

Apenas os dois clones de H. nitida, CPAA C 64 e CPAA C 65, mostraram-se compatíveis. Lieberei (1988) encontrou um teor muito baixo de glicosídeos cianogênicos nas folhas de $H$. nitida, o que conduziu à hipótese de que a incompatibilidade dos clones de copa com IPA 1 estaria relacionada com a cianogênese, embora as particularidades de localização intracelular, metabolismo e translocação dos compostos cianogênicos em Hevea (descritos na revisão de literatura), tornasse pouco provável uma relação simples de causa e efeito com o teor de glicosídeos cianogênicos nas folhas.

Para verificar a possibilidade de a incompatibilidade descrita estar relacionada com a cianogênese, bem como buscar um maior esclarecimento dessa relação, o trabalho objetivou estudar: a resposta à aplicação de soluções de cianeto de potássio $(\mathrm{KCN})$ e linamarina em caules jovens de clones de seringueira, em termos de manifestação de sintomas externos e internos e, no caso da linamarina, concentração de HCN livre; a ação "in vitro" do KCN no látex desses clones; a determinação de atividade das enzimas $\beta$-glicosidase, $\beta$-diglicosidase e $\beta$-cianoalaninasintase na casca dos clones estudados; o desenvolvimento de combinações de enxertos, tendo sempre como clone de painel o IPA 1 e como copa, clones de baixo potencial cianogênico (HCN-p); bem como, a dosagem de $\mathrm{HCN}$-p em folhas jovens e maduras de alguns desses clones de copa e de outros cujo resultado da enxertia já era previamente conhecido. 


\section{REVISÃO DE LITERATURA}

\subsection{Aspectos gerais}

A seringueira (Hevea brasiliensis Muell.-Arg.) é originária da Região Amazônica, onde as condições climáticas são mais favoráveis ao seu crescimento e à produção de látex. Porém, tais condições são também propícias a surtos epidêmicos severos do mal-das-folhas, enfermidade causada pelo fungo Microcyclus ulei (P. Henn.) v. Arx. Tal fato tem frustrado, há mais de seis décadas, as tentativas do estabelecimento da heveicultura na região, apesar dos esforços da pesquisa em termos de melhoramento genético e controle químico (Moraes, 1997).

A heveicultura expandiu-se no Brasil nas "áreas de escape" do Centro Oeste e Sudeste, caracterizadas por estação seca prolongada e intensa, onde foram plantadas, até 1998, 200.000 ha com seringueira, dos quais cerca de 39.000 ha em São Paulo, atualmente o maior produtor, com 26.478 toneladas, seguido do Mato Grosso, com 8.734 toneladas (Pinheiro, 1997).

Fora das "áreas de escape", a enxertia de copa com clones resistentes ao M. ulei apresenta-se, atualmente, como a única solução disponível para a heveicultura na América Latina, podendo ser também a única alternativa caso o mal-das-folhas ultrapasse a barreira climática existente nessas áreas. Em um contexto mais global, também representa a alternativa de solução caso ocorra a introdução dessa enfermidade no Sudeste da Ásia (Moraes, 1997).

A enxertia de copa é utilizada na Malásia e na Índia no cultivo de seringueira para a solução de problemas menos graves que o mal-das-folhas, tais como suscetibilidade à quebra das copas pelo vento e outras enfermidades das folhas (Rubber 
Research Institute of India, 1987 e Tan \& Leong, 1977). Nesses países, os clones utilizados como copas enxertadas são de $H$. brasiliensis, sendo registrados, inclusive, aumentos de produtividades com o uso de copas enxertadas (Yoon, 1972)

As primeiras tentativas de enxertia de copa com clones resistentes ao mal-dasfolhas, no Brasil, foram feitas em Belterra, município de Santarém, estado do Pará, com clones de $H$. brasiliensis, resistentes apenas às raças locais daquela época (Pinheiro et al., 1989). Vários experimentos, à época, demonstraram o efeito depressivo que copas enxertadas de outras espécies de Hevea exerciam sobre a produtividade do látex do clone de painel (Ostendorf, 1948; Lasschnit \& Volema, 1952; Langford, 1957; Radjino, 1969 e Bahia \& Sena Gomes, 1981). Tais resultados serviram de forte argumento para atribuir baixa prioridade à pesquisa de enxertia de copa como solução para a heveicultura na Amazônia sempre úmida. Além disso, havia, também, a expectativa de bons resultados com os procedimentos clássicos de melhoramento genético e com o controle químico do mal-das-folhas em seringais adultos. Porém, devido à variabilidade e mutabilidade do $M$. ulei, não foi possivel obter clones produtivos com resistência estável e o controle químico mostrou-se inviável nas condições da Amazônia (Moraes, 1997).

Os principais obstáculos à adoção dessa técnica da enxertia de copa para recuperação de seringais na Amazônia foram o efeito depressivo da produção de látex, causado por copas resistentes ao $M$. ulei, enxertadas em clones produtivos e suscetíveis, e os baixos índices de pegamento da enxertia de copa, o que pode estar associado à formação de processos de incompatibilidade (Moraes, 1997).

\subsection{Processo de incompatibilidade em enxertia}

Quando comparada aos animais, as plantas oferecem maior plasticidade, em se tratando do estabelecimento de união bem sucedida de tecidos vivos com composição genética diferente, uma vez que permitem a enxertia até entre gêneros diversos (Herrero, 1951). Apesar dessa maior tolerância das células vegetais em se adaptar às novas condições impostas pela simbiose forçada, não é incomum o desenvolvimento de processos de incompatibilidade de enxertia em plantas. Nessas condições, o termo 
incompatibilidade é definido como um fenômeno de senescência prematura causada por processos fisiológicos e bioquímicos (Feucht, 1988).

O gênero Hevea, embora consista de poucas espécies, exibe considerável variabilidade genética e morfológica, estando adaptado a uma ampla faixa de sítios ecológicos (D'Auzac et al., 1989). Essas variabilidades encontram-se marcadamente presentes entre os clones produtivos e os resistentes (Moraes, 1997), o que, dependendo do grau de antagonismo celular entre os componentes do enxerto, pode dificultar a conexão das duas plantas, impedindo que permaneçam vivas e subseqüentemente cresçam e se desenvolvam como uma única planta.

Hartman et al. (1990) classificam os tipos de incompatibilidade em três categorias: induzida por vírus, localizada e por translocação.

Incompatibilidade induzida por virus: caso em que um dos componentes do enxerto esteja infectado com vírus, porém em condição inativa, sem manifestação de qualquer sintoma, e o outro componente apresente reação de sensibilidade. A união não será bem sucedida, desenvolvendo sintomas semelhantes aos observados em condições de incompatibilidade. Esse tipo de incompatibilidade ainda não foi registrado em Hevea.

Incompatibilidade localizada: caso em que a reação aparece no ponto de união dos componentes do enxerto como resultado do contato direto entre células genotipicamente diferentes. Usando-se, como ponte, um terceiro componente que seja compativel às duas outras partes, os sintomas de incompatibilidade desaparecem e a planta pode se desenvolver normalmente. Muitos sintomas estão associados a esse tipo de incompatibilidade, destacando-se entre eles a descontinuidade do câmbio vascular.

Conforme mencionado na Introdução, há registros de pequeno número de casos de incompatibilidade localizada em Hevea.

Incompatibilidade por translocação: o uso de enxerto intermediário compativel não é capaz de reverter o quadro de incompatibilidade, sugerindo que substâncias translocadas do cavalo para o cavaleiro, ou do cavaleiro para o cavalo, estejam envolvidas. Nesse caso, observa-se a degeneração do floema e conseqüente restrição ao movimento dos carboidratos. 
Em seringueira esse tipo de incompatibilidade foi observada em enxertos de copa nas combinações cujo clone de painel foi o IPA 1 e os de copa, os provenientes de $H$. pauciflora e $H$. guianensis var. marginata. Nessas combinações, ocorreu a morte do clone de copa, em enxertos com três ou quatro lançamentos, cujo crescimento até essa fase foi bastante vigoroso, evidenciando boa conexão dos elementos condutores no tecido de união do enxerto. Como sintomas externos iniciais ocorreu um amarelecimento repentino das folhas do clone de copa, que morreram dentro de poucos dias, permanecendo presas ao caule, o qual também murchou e morreu poucos dias após (Moraes, 1999).

A morte do clone de copa foi precedida por necrose do caule do painel IPA 1, a partir de $3 \mathrm{~cm}$ a $5 \mathrm{~cm}$ abaixo da placa, ainda visível, do enxerto. A necrose estendeu-se por $10 \mathrm{~cm}$ a $15 \mathrm{~cm}$ ao longo do caule do IPA 1, do mesmo lado do caule onde se localiza a placa do enxerto, expandindo-se, depois, lateralmente, com anelamento completo, após o que, sobreveio a morte do enxerto (Moraes, 1999).

Quando os enxertos ainda estavam em pleno crescimento, deixou de haver exsudação de látex da casca do IPA 1, na mesma área onde depois ocorreu necrose. A falta de exsudação foi devida à coagulação do látex nos laticíferos, comprovada pela coloração com Sudam III, em cortes à mão livre, de casca não tratada com fixador. A ausência de exsudação do látex, ocorreu em plantas já com dois lançamentos maduros; no início, a casca foi aparentemente sadia, apresentando-se amarelada dentro de uma a duas semanas, passando, depois, a apresentar uma camada de tecido necrosado entre o floema condutor e a epiderme, que se expandiu, atingindo toda a espessura da casca (Moraes, 1999).

Combinações compatíveis foram obtidas utilizando como painel o clone IPA 1 e como copa, clones de $H$. nitida (Moraes, 1999), cujo potencial cianogênico é baixo (Lieberei, 1988).

Dentre os compostos translocáveis através dos componentes do enxerto, que são capazes de provocar esse tipo de incompatibilidade, destacam-se os que, através de sua hidrólise, liberam ácido cianídrico ( $\mathrm{HCN})$, os chamados cianogênicos. 
Gur (1957), estudando enxertos de marmeleiro sob pereira, observou que o glicosídeo cianogênico prunasina ocorre no marmeleiro e não na pereira. Nas combinações incompatíveis há, na casca do caule da pereira, hidrólise mais rápida do glicosídeo translocado. Após a aplicação de amigdalina no caule da pereira, esse mesmo autor verificou o aparecimento na casca do caule dos mesmos distúrbios anatômicos causados pelo acúmulo de HCN nas combinações incompatíveis, com bloqueio do sistema condutor do floema. A amigdalina é um diglicosídeo, que perdendo uma unidade de glicose, transforma-se no monoglicosídeo prunasina, que, então, sofre hidrólise catalisada por $\beta$-glicosidase, liberando $\mathrm{HCN}$, como mostra a reação:

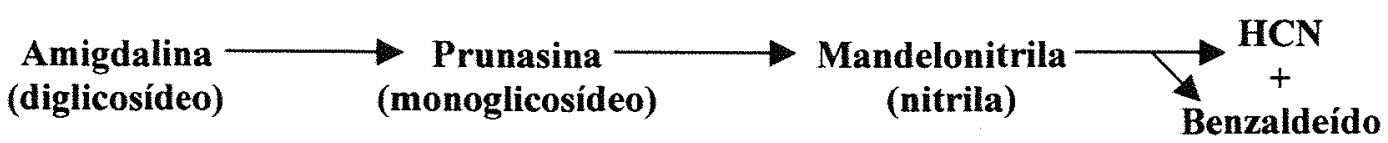

\subsection{Cianogênese}

O fenômeno da cianogênese em plantas superiores é relativamente comum, aproximando-se de 2.000 o número de espécies com conhecida capacidade cianogênica. Essas espécies são gimnospermas e angiospermas, tanto mono quanto dicotiledôneas, e estão distribuídas entre aproximadamente 110 familias. Destacam-se, por apresentarem maior número de espécies cianogênicas, as familias: Rosaceae (150 espécies), Leguminosae (125), Gramineae (100), Araceae (50), Compositae (50), Euphorbiaceae (50) e Passifloraceae (30) (Conn, 1980).

Outros organismos, como certas bactérias e fungos e até mesmo alguns tipos de insetos, também são capazes de produzir $\mathrm{HCN}$, diferenciando-se das plantas, principalmente, quanto a natureza das substâncias que o liberam (Conn, 1980).

Em plantas superiores, os compostos identificados como capazes de liberar $\mathrm{HCN}$ são denominados de substâncias cianogênicas e podem ser de dois tipos: os glicosídeos cianogênicos e os lipídeos cianogênicos. Embora o número de espécies de plantas que apresentam cianogênese seja grande, o número de glicosídeos ou lipídeos cianogênicos é pequeno, em um total de apenas 17 . Somente quatro são de natureza lipídica, ocorrendo em uma única familia, Sapindaceae (Conn, 1980). 
$\mathrm{Na}$ família Euphorbiaceae, os glicosídeos cianogênicos mais comumente encontrados são linamarina (2-hidroxisobutironitrila- $\beta$-D-glucopiranosideo) e (R)lotaustralina [(R)-(2-hidroxi-2-metilbutironitrila- $\beta$-D-glucopiranosídeo)], ocorrendo, em geral, na mesma planta, embora não necessariamente na mesma proporção. Estudos sobre a biossíntese desses glicosídeos revelaram que a produção de linamarina e lotaustralina decorre da ação de enzimas sobre valina e isoleucina respectivamente (Hahlbrock \& Conn, 1971). Lieberei et al. (1986) verificou a presença desses dois glicosídeos em várias espécies do gênero Hevea, encontrando valores para a quantidade de lotaustralina sempre inferiores aos de linamarina, não ultrapassando $3 \%$ do conteúdo total de glicosídeos cianogênicos, não tendo sido detectada em H. brasiliensis. No entanto, pequenas quantidades de lotaustralina foram observadas por Mallika et al. (1991) nessa espécie de Hevea.

A cianogênese está presente em nove das onze espécies existentes de Hevea (Lieberei, 1988). Em 87 clones, oriundos do cruzamento de várias espécies, foi verificada a liberação de $\mathrm{HCN}$ em vários órgãos, como folhas, raízes e pecíolos. No caso de clones oriundos exclusivamente de $H$. brasiliensis não houve liberação de HCN no látex, mesmo após a adição da enzima que catalisa a hidrólise do glicosídeo cianogênico (Lieberei, 1986).

O conteúdo dos glicosídeos cianogênicos em Hevea varia muito entre espécies. Em uma única planta varia com o órgão, bem como com o estádio de desenvolvimento deste (Lieberei, 1988). Durante o desenvolvimento da folha, cujos estádios foram definidos por Dijkman (1951), o estádio C corresponde ao de maior conteúdo desses glicosídeos, verificando-se um significante declínio quando a folha atinge o estádio D (Lieberei, 1988).

\subsubsection{Processos de liberação e metabolismo do HCN}

A liberação do HCN ocorre quando a planta sofre algum ferimento. Em plantas intactas, as enzimas que promovem a quebra dos glicosídeos cianogênicos, chamadas genericamente de $\beta$-glicosidases, encontram-se separadas destes por compartimentação (Conn, 1980). 
$\mathrm{Na}$ seringueira, por ocasião do ferimento, os glicosídeos cianogênicos armazenados no vacúolo (Gruhnert et al., 1994) são liberados e entram em contato com a $\beta$-glicosidase existente nas paredes das células. Pela ação da $\beta$-glicosidase, o glicosídeo é separado nas suas partes açúcar e aglicona ( $\alpha$-hidroxinitrilas ou cianohidrinas), que, por sua vez, é quebrada em $\mathrm{HCN}$ e carbonila pela atividade da $\alpha-$ hidroxinitrilase (Selmar, 1986). O HCN livre pode se difundir rapidamente através do tecido vegetal ou pode ligar-se a carbonilas ou iminas, retardando sua liberação (Lieberei, 1988).

Em Hevea tem-se observado, ainda, a desintoxicação por fixação enzimática catalisada pela $\beta$-cianoalaninasintase, enzima presente em alta atividade, especialmente em folhas, cotilédones e raízes muito jovens (Lieberei, 1988). Em mamíferos a desintoxicação de $\mathrm{HCN}$ ocorre pela ação da enzima rodanase que, segundo Chew (1973), também está presente no gênero Hevea. As reações para liberação e refixação do $\mathrm{HCN}$ foram representadas por Lieberei (1988):

\section{Liberação}

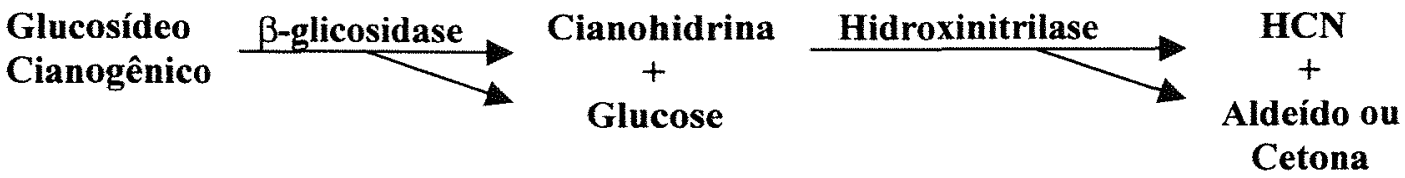

\section{Refixação}

A

$$
\mathrm{HCN}+\begin{gathered}
\text { Carbonilas } \\
\text { ou Iminas }
\end{gathered} \longrightarrow \begin{gathered}
\text { Cianohidrinas ou } \\
\text { Cianoaminas }
\end{gathered}
$$

B

$\mathrm{HCN}+$ Cisteína $\stackrel{\beta-\text { Cianoalaninasintase }}{\longrightarrow} \beta$-Cianoalanina $\stackrel{\mathrm{H}_{2} \mathrm{O}}{\longrightarrow}$ Asparagina

\subsubsection{Enzimas envolvidas nos processos de liberação e metabolismo do HCN na planta}

Selmar et al. (1987b) estudaram a $\beta$-glicosidase linamarase, caracterizando-a por apresentar baixa especificidade, portanto, com amplo espectro de substratos, 
promovendo a quebra de todos os $\beta$-glicosídeos e $\beta$-galactosídeos, que ocorrem no gênero Hevea. Usando p-nitrofenil-glucosídeo ( $\mathrm{p}-\mathrm{NPG}$ ) como substrato, a enzima exibiu um pH ótimo de 5,6. Em solução a $2 \mathrm{mmol} \mathrm{L}^{-1}$, desse mesmo substrato, e incubação de dez minutos, encontraram uma atividade máxima da enzima a $62^{\circ} \mathrm{C}$. Observaram, ainda, uma baixa sensibilidade às variações de concentração das soluções tampões empregadas na sua extração. Os valores de $\mathrm{K}_{m} \mathrm{e}_{m}$ determinados foram maiores para os substratos linamarina $\left(7,6 \mathrm{mmol} \mathrm{L}^{-1}\right.$ e $\left.191.000 \mathrm{mmol} \mathrm{mg}^{-1} \mathrm{~min}^{-1}\right)$ e lotaustralina $\left(7,7 \mathrm{mmol} \mathrm{L}{ }^{-1} \mathrm{e}\right.$ $95.000 \mathrm{mmol} \mathrm{mg}^{-1} \mathrm{~min}^{-1}$ ), quando comparados aos valores obtidos com outros substratos, não havendo uma relação direta entre eles, ou seja, enquanto os $\mathrm{K}_{m}$ para esses dois substratos foi praticamente o mesmo, $o$ valor do $V_{m}$ para linamarina foi o dobro.

A atividade da linamarase em Hevea varia dependendo do órgão vegetal, bem como do seu estádio de desenvolvimento (Lieberei, 1988). Nas folhas os picos de atividade da linamarase foram observados nos estádios $B_{1}$ e $C$ (Selmar et al., 1989), correspondendo aos picos de conteúdo dos glicosídeos cianogênicos nesse órgão (Lieberei, 1988).

Nas amostras de linamarase purificada, extraída de folhas de seringueira, foi verificada a ocorrência de 14 formas decorrentes de agregações do monômero de 64.000 D. As formas monoméricas e oligoméricas são enzimaticamente ativas e interconversíveis, inexistindo oligômeros inativos (Selmar et al., 1987b).

Marcinowski et al. (1979) mostraram que os precursores da lignina, coniferina e seringina, são hidrolisados durante a lignificação por glicosidases localizadas na parede celular, sendo esse processo similar em todas as plantas superiores.

Em Hevea a única $\beta$-glicosidase detectada é a linamarase, encontrada unicamente no apoplasma. Esse fato indica que essa enzima é a responsável pela hidrólise de todos os $\beta$-glicosídeos que ocorrem naturalmente no gênero, incluindo coniferina; devendo, portanto, estar, também, envolvida nos processos de lignificação além da cianogênese (Selmar et al., 1987b e Gruhnert et al., 1994).

A $\alpha$-hidroxinitrilase, ao contrário da $\beta$-glicosidase, é encontrada inteiramente no interior da célula vegetal (Gruhnert et al., 1994) e catalisa a dissociação da acetona cianohidrina e mandelonitrila (Selmar et al., 1989). 
Além da ação da hidroxinitrilase, a liberação do $\mathrm{HCN}$ das cianohidrinas ocorre espontaneamente em meio alcalino, no entanto, a faixa ótima de $\mathrm{pH}$ para a linamarase é de 5,6 (Selmar et al., 1987b), nessas condições a liberação espontânea ocorre muito lentamente (Cooke, 1978). Portanto, para uma rápida cianogênese é necessário que ambas as enzimas, $\beta$-glicosidases e hidroxinitrilases, estejam presentes em quantidades adequadas (Lieberei, 1988).

Selmar et al. (1989) estudaram a razão existente entre as atividades das enzimas hidroxinitrilase e linamarase em clones oriundos do cruzamento entre várias espécies de Hevea, observando que, apesar da grande variação encontrada entre clones, a razão, em $70 \%$ das plantas analisadas, variou entre 1 e 4 , e a razão para mais de $90 \%$ das plantas foi maior do que 1,1 , sendo que a média foi de $2,0(n=32)$. Havendo portanto, na maioria dos casos, valores de atividade superiores para a hidroxinitrilase do que para linamarase. Além disso, apesar dos valores observados para a atividade de ambas as enzimas variarem significativamente durante o desenvolvimento da folha de uma única planta, esses mostraram-se sempre maiores para a hidroxinitrilase. Portanto, a limitação da cianogênese em Hevea está praticamente associada à atividade da enzima linamarase.

A enzima envolvida no metabolismo vegetal do $\mathrm{HCN}$ é a $\beta$-cianoalaninasintase $(\beta$-CAS), que catalisa a reação entre o $\mathrm{HCN}$ e a cisteína para formar $\beta$-cianoalanina e sulfeto de hidrogênio (Floss et al., 1965; Blumenthal, et al., 1968 e Castric et al., 1972). Esse metabolismo é muito vantajoso para as plantas, já que o produto $\beta$-cianoalanina pode ser metabolizado para asparagina, que, por sua vez, pode ser incorporada no metabolismo geral da planta (Miller \& Conn, 1980).

Em espécies não cianogênicas a presença dessa enzima está relacionada com o mecanismo de desintoxicação na síntese endógena de etileno, onde há formação de $\mathrm{HCN}$ na fase em que o ácido carboxílico aminociclopropano (ACC) é transformado em etileno (Peiser et al., 1984 e Goudey et al., 1989).

A síntese da $\beta$-CAS é no citoplasma e sua localização nos mitocôndrios, onde o sequestro do $\mathrm{HCN}$ impede que esta reaja com o citocromo $\mathrm{aa}_{3}$, inbindo a respiração normal (Peiser et al., 1984). 
Miller \& Conn (1980) estudaram o metabolismo do $\mathrm{HCN}$ em várias espécies de plantas superiores, pertencentes a gêneros diversos, incluindo espécies cianogênicas e não cianogênicas. Esses autores encontraram uma tendência geral de relação direta entre a atividade da enzima e o potencial cianogênico das plantas.

Em Hevea. entretanto, Umbach (1989) encontrou grande variação de atividade de $\beta$-CAS, expressa em relação ao peso das folhas, nos oito clones estudados, sem proporcionalidade com o potencial cianogênico. Por exemplo, em $H$. nitida a atividade de $\beta$-CAS em folhas do estádio $B_{1}$ foi de $2,4 \eta$ mol de $\mathrm{H}_{2} \mathrm{~S} \mathrm{~g}^{-1} \mathrm{~s}^{-1}$, enquanto no clone RRIM 600, com HCN-p muito mais alto, a atividade em folhas no mesmo estádio foi de apenas $0,5 \eta \mathrm{mol}$ de $\mathrm{H}_{2} \mathrm{~S} \mathrm{~g}^{-1} \mathrm{~s}^{-1}$. Foi, entretanto, encontrada proporcionalidade entre $\beta$ CAS e HCN-p, quando comparados os valores em folhas, caule e raizes de um mesmo clone, com niveis mais baixos de $\beta$-CAS e HCN-p no caule e ausência de $\beta$-CAS nas raizes, correspondendo a um $\mathrm{HCN}$-p muito baixo.

\subsubsection{Função da cianogênese e dos compostos cianogênicos na planta}

A função biológica mais freqüentemente atribuída à cianogênese em plantas é a de proteção contra herbívoros, devido às propriedades tóxicas do $\mathrm{HCN}$ liberado pelo tecido vegetal que sofreu ferimento (Kakes, 1990). No entanto, espécies cianogênicas como a seringueira, são atacadas por insetos, ou mesmo mamíferos. Além disso, em Hevea a capacidade de liberação de $\mathrm{HCN}$ está diretamente associada à susceptibilidade ao ataque do fungo $M$. ulei, pois a germinação dos seus esporos é favorecida por altos níveis de cianeto (Lieberei, 1988) que, por sua vez, inibem a síntese de fitoalexinas, particularmente da escopoletina, tóxica a esse patógeno (Lieberei et al., 1989).

O papel que os compostos capazes de liberar HCN desempenham em plantas intactas, sem ferimentos e não infectadas, é ainda bastante controverso. Selmar et al. (1990) consideram que esses produtos secundários podem agir como armazenadores de nitrogênio em sua forma reduzida.

Em algumas espécies têm sido observadas indicações de que desempenham diferentes funções na germinação das sementes (Lieberei et al., 1986). Em Phaseolus lunatus $\mathrm{L}$. os glicosídeos cianogênicos são translocados dos tecidos de armazenamento (cotilédones) para os órgãos em crescimento das plantas jovens, não havendo perda do 
potencial cianogênico durante o desenvolvimento da muda e o conteúdo do precursor cianogênico linamarina permaneceu constante por toda planta, durante 25 dias (Clegg et al., 1979). Outros trabalhos mostraram que os glicosídeos foram metabolizados dentro da planta (Bough \& Gander, 1971), podendo o HCN, liberado durante o metabolismo, ser usado para suprimento de nitrogênio via $\beta$-cianoalanina e asparagina, como já mencionado anteriormente.

Nas sementes de seringueira os glicosídeos cianogênicos são armazenados no endosperma. Durante o desenvolvimento da plântula, o conteúdo desses glicosídeos é reduzido para $15 \%$ do conteúdo original, sem perda de $\mathrm{HCN}$ para o meio, nem aumento de HCN-p de raizes, folhas ou caule. Tais fatos vêm a ser um forte indício de que, em Hevea, os compostos cianogênicos não apresentam, como função primária a proteção contra herbívoros, mas sim a de compostos armazenadores de nitrogênio para síntese de proteína, pelo menos na fase de germinação (Lieberei et al., 1986 e Selmar et al., 1987b).

\subsubsection{Transporte dos compostos cianogênicos no interior da planta}

Em plântulas de Hevea a enzima $\beta$-CAS, capaz de metabolizar o HCN liberado pela hidrólise dos glicosídeos cianogênicos, encontra-se nos cotilédones, folhas e raízes e os glicosídeos, no endosperma da semente. Portanto, para que possa ocorrer a metabolização do $\mathrm{HCN}$ é necessário que esses glicosídeos sejam transportados até o local de ocorrência da enzima. Como a linamarase, $\beta$-glicosidase do gênero Hevea responsável pela quebra dos glicosídeos cianogênicos, ocorre no apoplasma, Selmar (1993) estudou um possível modelo que explicasse o transporte da linamarina em plântulas, sem a sua, aparentemente inevitável, degradação.

Nesse modelo, à linamarina existente no endosperma, seria acrescentada uma nova unidade de glicose, transformando-se em um diglicosídeo cianogênico, denominado linustatina (Figura 1), que não sofre a ação da linamarase, podendo, então, ser translocado do endosperma para o cotilédone ou folhas sem sofrer hidrólise.

Em plantas adultas de seringueira ocorre uma maior concentração de compostos cianogênicos nas folhas jovens, não tendo sido observadada ainda sua translocação para 
outras partes da planta, o que poderia ocorrer de forma semelhante ao verificado em plântulas.<smiles>CC(C)OC(C)(C)C#N</smiles>

Linamarina

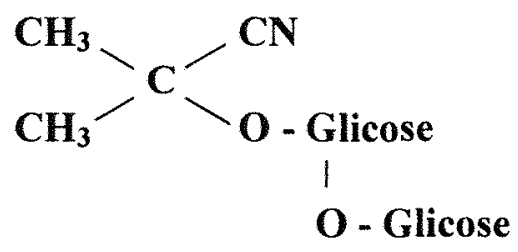

Linustatina

Figura 1. Glicosídeo (linamarina) e diglicosídeo cianogênico (linustatina) que ocorrem em Hevea brasiliensis.

A constatação da presença de linustatina em exsudado obtido do endosperma da semente (Selmar et al., 1987b) e dos nectários extraflorais das folhas, cuja composição qualitativa do néctar corresponde ao do fluido do floema, sendo observado, ainda, nesse caso a completa ausência de linamarina (Selmar, 1993); o conteúdo superior desse diglicosídeo em sementes armazenadas por seis dias, comparado ao conteúdo em sementes frescas (Selmar et al., 1987) e a ausência no apoplasma da $\beta$-diglicosidase, linustatinase, responsável pela hidrólise da linustatina (Gruhnert et al., 1994), são evidências que propiciam à teoria do transporte da linamarina via linustatina em Hevea, grande credibilidade.

A ação da $\beta$-diglicosidase sobre a linustatina ocorre de modo simultâneo, ou seja, os produto obtidos são um dissacarídeo, gentiobiose, e uma cianohidrina, e não de modo sequencial, cujos produtos seriam linamarina e uma molécula de açúcar. Tal fato facilita a metabolização do $\mathrm{HCN}$ e, portanto, a utilização do átomo de nitrogênio para a síntese de compostos não cianogênicos (Selmar et al., 1991).

O significado fisiológico dos compostos cianogênicos como reserva de nitrogênio em Hevea, são indicados ainda pelas seguintes observações: durante o desenvolvimento da plântula o decréscimo no conteúdo de linamarina no endosperma da semente é acompanhado do aumento da atividade das enzimas $\beta$-diglicosidase e $\beta$-CAS (Selmar et al., 1988) e a detecção de proteínas e outros compostos marcados $\operatorname{com}{ }^{14} \mathrm{C}$ nas raízes, folhas e caules, após a aplicação de linustatina marcada com ${ }^{14} \mathrm{C}$ em cotilédones de plântulas de Hevea (Selmar et al., 1993). 


\section{MATERIAL E MÉTODOS}

\subsection{Localização}

As coletas e as análises dos materiais vegetais foram realizadas no Centro de Pesquisa Agroflorestal da Amazônia Ocidental (Embrapa-CPAA), localizado no municipio de Manaus, Estado do Amazonas.

\subsection{Resposta à aplicação de $\mathrm{KCN}$, em dose única}

As aplicações foram efetuadas em ramos de 7 a 9 meses, com cerca de $1 \mathrm{~cm}$ de diâmetro no entrenó do penúltimo lançamento, brotados do caule principal decapitado, de plantas de jardim clonal, do clone de painel IPA 1 ( H. brasiliensis), que apresenta sintomas de incompatibilidade quando enxertado com clones de copa provenientes de $H$. pauciflora e H. guianensis var. marginata, e dos clones de painel Fx 4098 e Fx 3864 (H. brasiliensis) que são compatíveis com essas mesmas copas.

$\mathrm{O} \mathrm{KCN}$ foi aplicado em solução aquosa com dimetilsulfóxido (DMSO), 0,05\%, em duas repetições de cada uma das seguintes concentrações em $\mathrm{mg} \mathrm{L}^{-1}: 0,0064 ; 0,032$; 0,$16 ; 0,8 ; 4,0 ; 20,0$ e 100,0 .

Para a aplicação das soluções, os ramos foram cortados abaixo do penúltimo lançamento com folhas maduras, com retirada dos coágulos de látex e certificação da parada completa de escoamento.

Em cada ramo cortado foi realizada uma só aplicação de $2 \mathrm{~mL}$ de cada solução, contidos em segmentos de $5 \mathrm{~cm}$ de tubo plástico de paredes semi-elásticas, com $1 \mathrm{~cm}$ de diâmetro interno, tendo cerca de $1,5 \mathrm{~cm}$ inseridos ao redor do caule, a partir do topo cortado, com vedação de fita veda rosca entre a parede do tubo e a epiderme do caule. 
Após a aplicação da solução e a verificação da ausência de vazamento, os tubos foram cobertos com papel alumínio.

No clone Fx 4098 foi aplicada, adicionalmente, a mesma série de diluições de $\mathrm{KCN}$ em solução aquosa de DMSO $0,05 \%$, acrescida de sacarose $0,1 \mathrm{~mol} \mathrm{~L}^{-1}$, para verificar a ocorrência de um possível efeito de cotransporte.

A verificação da exsudação do látex foi efetuada por puncturas com estilete de 1 mm de diâmetro. Ao final das observações foram realizados cortes da casca a mão livre, corados em Sudam III, sem prévia fixação, para observação microscópica.

\subsection{Resposta à aplicação contínua de $\mathrm{KCN}$}

As aplicações foram efetuadas como na aplicação de uma única dose de $2 \mathrm{~mL}$ por planta, descrita no item anterior, mantendo-se a solução nos tubos com reaplicações. Foram testadas as seguintes concentrações:

Clone IPA $1-0,032 \mathrm{mg} \mathrm{L}^{-1}$ e $0,16 \mathrm{mg} \mathrm{L}^{-1}$

Clone Fx $4098-0,16 \mathrm{mg} \mathrm{L}^{-1}$ e $20 \mathrm{mg} \mathrm{L}^{-1}$

\subsection{Resposta à aplicação de linamarina}

A técnica de aplicação da linamarina foi idêntica à da aplicação contínua de $\mathrm{KCN}$, porém com volume inicial de $3 \mathrm{~mL}$, durante cinco dias. Foram também registrados os efeitos sobre o escoamento do látex, a ocorrência de sintomas externos de necrose na casca e realizadas observações microscópicas em cortes de casca a mão livre. Foi incluído um tratamento testemunha com solução aquosa de DMSO 0,05\%. As concentrações testadas de linamarina em $\mathrm{mg} \mathrm{L}^{-1}$ foram: 0,$04 ; 0,2 ; 1,0 ; 5,0 ; 25,0$ e 125,0 .

\subsection{Ação do cianeto na coagulação do látex in vitro}

De plantas adultas dos clones Fx 3864, Fx 4098 e IPA 1, sangradas duas vezes por semana em meia espiral, sem estimulação, foi coletado látex em frascos de vidro de $50 \mathrm{~mL}$, circundados com gelo em copo de plástico e transportados em caixa de poliestireno. 
Em $20 \mathrm{~mL}$ do látex de cada clone, previamente equilibrado com a temperatura ambiente, foi aplicada, com bureta, uma solução de $\mathrm{KCN}, 300 \mathrm{mmol} \mathrm{L}^{-1}$, com agitação vigorosa a cada aplicação de $0,1 \mathrm{~mL}$, até que se verificasse a coagulação, dentro de 20 segundos após a aplicação de cada alíquota, registrando-se o volume consumido da solução de $\mathrm{KCN}$.

\subsection{Concentração de $\mathrm{HCN}$ livre nos caules submetidos a diferentes tempos de exposição à solução de linamarina}

A técnica de aplicação da linamarina foi a mesma descrita para o item anterior, utilizando-se apenas a concentração de $6 \mathrm{mg} \mathrm{L}^{-1}$, em solução aquosa de DMSO, 0,05\%. As aplicações foram efetuadas em caules jovens dos clones IPA 1 e Fx 3864, com duas repetições para cada tratamento, sendo considerada cada repetição uma planta e os tratamentos os diferentes tempos de exposição do caule à ação da linamarina: 6 horas, 12 horas, 16 horas e 24 horas e ainda um tratamento testemunha, sem aplicação de linamarina. Os resultados foram submetidos à análise de variância, completada pelo teste $\mathrm{F}$ e, por se tratarem de fatores quantitativos, realizou-se a análise de regressão polinomial com significância de $1 \%$ de probabilidade.

\subsubsection{Preparo da amostra}

O método utilizado para extração foi adaptado de Cooke (1978) e Selmar (1986).

Os caules foram coletados nos tempos determinados para cada tratamento. No laboratório, retirou-se $1 \mathrm{~g}$ de casca, a partir da ponta do caule que estava em contato com a solução de linamarina. As cascas foram picadas e moídas em gral com pistilo pré resfriado com a adição de $4 \mathrm{~mL}$ de solução também pré resfriada de ácido ortofosfórico, 0,067 mol L $\mathrm{L}^{-1}$, que, segundo Cooke (1978), inativa a enzima, e de $500 \mathrm{mg}$ de areia lavada com solução de ácido clorídrico, 10\%, solução sulfocrômica e, por fim, água destilada.

O macerado obtido foi centrifugado a 20.000 g por 14 minutos, entre zero e seis graus centígrados. O sobrenadante foi então transferido para frasco de vidro com capacidade para $30 \mathrm{~mL}$. 


\subsubsection{Determinação de HCN livre}

Do sobrenadante obtido após centrifugação, foi retirado $0,1 \mathrm{~mL}$ para outro frasco idêntico ao anterior, ao qual adicionou-se $0,45 \mathrm{~mL}_{\text {de }} \mathrm{NaH}_{2} \mathrm{PO}_{4},\left(0,067 \mathrm{~mol} \mathrm{~L}^{-1}\right), 0,6 \mathrm{~mL}$ de $\mathrm{NaOH},\left(0,2 \mathrm{~mol} \mathrm{~L}^{-1}\right)$ e $3,85 \mathrm{~mL}$ de água destilada, num total de $5 \mathrm{~mL}$. Para o branco

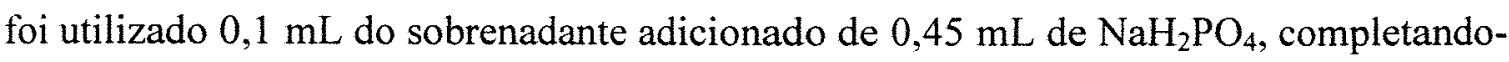
se $o$ volume para $5 \mathrm{~mL}$ com água destilada.

A seguir, foram acrescentados os reagentes do kit Spectroquant da Merck para determinação de cianeto em soluções, nas quantidades adequadas para amostras de 5 mL. A leitura da absorvância a $585 \mathrm{~nm}$ foi feita cinco minutos após a adição dos reagentes, tempo necessário para o desenvolvimento da coloração. O cálculo da quantidade de cianeto liberado, por grama de matéria fresca de casca, foi feito com base em curva padrão de cianeto, nas concentrações em $\mathrm{mg} \mathrm{L}^{-1}$ de 0,$1 ; 0,2 ; 0,3 ; 0,4$ e 0,5 .

\section{7 Atividade da $\beta$-cianoalaninasintase ( $\beta$-CAS)}

A atividade da enzima foi determinada na casca do caule dos clones IPA 1, Fx 4098 e Fx 3864 em três repetições para cada clone, sendo cada repetição uma planta. Os resultados foram submetidos à análise de variância e a comparação de médias foi efetuada pelo teste de Tukey, ao nível de $1 \%$ de probabilidade.

A homogeneização das amostras foi realizada em gral com pistilo resfriados com $1 \mathrm{~g}$ de casca do caule em $2 \mathrm{~mL}$ de tampão tris/ $\mathrm{HCl} 50 \mathrm{mmol} \mathrm{L}^{-1}, \mathrm{pH} 8,2$, também resfriado. Esse homogeneizado foi centrifugado por uma hora a $20.000 \mathrm{~g}$, entre zero e seis graus centígrados. Transferiu-se $1 \mathrm{~mL}$ do sobrenadante para frasco de vidro com capacidade para $30 \mathrm{~mL}$, e adicionou-se $0,5 \mathrm{~mL}$ de $\mathrm{KCN}, 50 \mathrm{mmol} \mathrm{L}^{-1}$, diluído em tampão tris $50 \mathrm{mmol} \mathrm{L}^{-1}$, pH 8,2, e em seguida, $0,5 \mathrm{~mL}$ de l-cisteína, $10 \mathrm{mmol} \mathrm{L}^{-1}$, diluída no mesmo tampão. Incubou-se por 30 minutos a $30^{\circ} \mathrm{C}$

Em seguida acrescentou-se a mistura $0,5 \mathrm{~mL}$ de $\mathrm{N}$-N-dimetil-p-fenilenodiamina

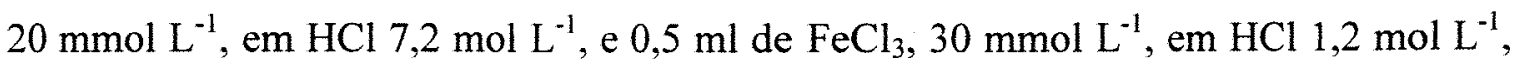
obtendo-se um volume final de $3 \mathrm{~mL}$. Deixou-se em repouso por 20 minutos a $30^{\circ} \mathrm{C}$, após o que foi feita a centrifugação a $1.000 \mathrm{~g}$ por 10 minutos. As soluções de cisteína e 
de $\mathrm{N}$-N-dimetil-p-fenilenodiamina foram preparadas alguns minutos antes do uso, já as soluções de $\mathrm{FeCl}_{3}$ e de $\mathrm{KCN}$ foram preparadas semanalmente.

As leituras de absorvância a $650 \mathrm{~nm}$, foram comparadas com curva padrão de $\mathrm{Na}_{2} \mathrm{~S}$, de $0,04 \mathrm{mmol} \mathrm{L}^{-1}$ a $0,167 \mathrm{mmol} \mathrm{L}^{-1}$, a partir de solução estoque de $\mathrm{Na}_{2} \mathrm{~S}, 0,1 \mathrm{~mol}$ $\mathrm{L}^{-1}$, titulada por iodometria, após precipitação do sulfeto com cloreto de zinco amoniacal, de acordo com Scott (1939). O tiossulfato $0,1 \mathrm{~N}$, para dosagem do excesso de iodo, na titulação do $\mathrm{Na}_{2} \mathrm{~S} 0,1 \mathrm{~N}$, foi titulado com permanganato $0,1 \mathrm{~N}$, titulado, por sua vez, com oxalato de sódio 0,1 N (Morita \& Assumpção, 1990).

Como branco foram utilizados, separadamente, $1 \mathrm{~mL}$ do extrato da enzima diluído em $2 \mathrm{~mL}$ do tampão tris e o mesmo volume das soluções dos quatro reagentes (0,5 mL de cada), com $1 \mathrm{~mL}$ do tampão tris. A soma das absorvâncias dos dois brancos, para cada amostra, foi subtraída da absorvância das amostras

\subsection{Atividade da $\beta$-glicosidase (linamarinase)}

A atividade da enzima foi determinada na casca do caule dos clones IPA 1, Fx 4098 e Fx 3864 em três repetições para cada clone, sendo cada repetição uma planta. Os resultados foram submetidos à análise de variância e a comparação de médias foi feita pelo teste de Tukey, ao nível de $1 \%$ de probabilidade.

\subsubsection{Extração, semi purificação e concentração da enzima}

Um grama de casca do último lançamento, com folíolos maduros, foi recortada em pedaços retangulares de aproximadamente $2 \mathrm{~mm} \times 3 \mathrm{~mm}$ e moída em gral de porcelana pré resfriado, com $4 \mathrm{~mL}$ de $\mathrm{NaH}_{2} \mathrm{PO}_{4}, 0,067 \mathrm{~mol} \mathrm{~L}^{-1}$. O extrato foi decantado, após compressão do resíduo fibroso que foi moído novamente com $5 \mathrm{~mL}$ de $\mathrm{NaH}_{2} \mathrm{PO}_{4}$, $0,067 \mathrm{~mol} \mathrm{~L}^{-1}$, procedendo-se de modo idêntico ao da primeira extração.

O extrato final, livre da maior parte do resíduo fibroso foi centrifugado a 20.000 $\mathrm{g}$ por 1 hora, entre zero e seis graus centígrados. O sobrenadante foi filtrado em membrana Milipore, tipo PSDE, sob pressão de 2,5 bárias e lavado 3 vezes, com filtração nas mesmas condições, com $30 \mathrm{~mL}$ de tampão de fosfato, $\mathrm{pH} 6,5,10 \mathrm{mmol} \mathrm{L}^{-1}$, a cada lavagem, para eliminação de pigmentos e possíveis inibidores da enzima. $O$ 
volume final do extrato foi reduzido para $5 \mathrm{~mL}$, na última filtração, o qual foi guardado em geladeira, para uso oportuno.

\subsubsection{Determinação da atividade da enzima}

Meio de incubação:

- $0,5 \mathrm{~mL}$ de p-nitrofenilglicopiranosídeo, $20 \mathrm{mmol} \mathrm{L}^{-1}$, em tampão McIlvaine (1921), pH 5,6

- $2,4 \mathrm{~mL}$ de água destilada

- $0,1 \mathrm{~mL}$ do extrato da enzima

- Total de $3 \mathrm{~mL}$

Tempo de incubação: 10 minutos, a $30^{\circ} \mathrm{C}$

Após esse período adicionou-se $2 \mathrm{~mL}$ de $\mathrm{Na}_{2} \mathrm{CO}_{3}, 0,5 \mathrm{~mol} \mathrm{~L}^{-1}$, para paralisar a atividade da enzima e evidenciar a coloração do p-nitrofenol liberado. A leitura da absorvância foi feita a $400 \mathrm{~nm}$ e o cálculo da quantidade de p-nitrofenol liberado, por grama de matéria fresca de casca, por minuto, com base em curva padrão de pnitrofenol, nas concentrações em $\mathrm{mmol} \mathrm{L}^{-1}$ de 0,$02 ; 0,04 ; 0,08 \mathrm{e} 0,1$.

Em uma repetição de cada clone, foi também determinada a atividade de $\beta$ glicosidase nas frações do filtrado na membrana.

\subsection{Enxertia de clones de copa de baixo potencial cianogênico, no clone IPA 1}

Foram enxertados os clones F 4512 (H. benthamiana), PL 22, PUA 5 e PUA 9 (H. pauciflora) cujo potencial cianogênico (HCN-p) é muito baixo (Lieberei, 1988) e como contraprova, o clone CPAA C 13 (H. pauciflora $x$ H. guianensis var marginata), com o qual já havia sido verificada anteriormente a incompatibilidade por translocação com o IPA 1 sem contudo se ter conhecimento de seu potencial cianogênico.

As enxertias foram efetuadas em ramos laterais de plantas de IPA 1 decapitadas em jardim clonal. 


\subsection{Atividade da $\beta$-diglicosidase (linustatinase)}

\subsubsection{Extração, semi purificação e concentração da enzima}

Foram adotados os mesmos procedimentos da determinação da atividade de $\beta$ glicosidase, porém com redução final do volume do extrato para $2 \mathrm{~mL}$.

\subsubsection{Determinação da atividade da enzima}

As determinações foram feitas nos extratos da enzima de acordo com o método descrito por Selmar (1986).

Meio de incubação:

- $2 \mathrm{~mL}$ de amigdalina, $12,4 \mathrm{~mol} \mathrm{~L} \mathrm{~L}^{-1}$, em tampão Mcllvaine $50 \mathrm{mmol} \mathrm{L} \mathrm{L}^{-1}, \mathrm{pH}$ 4,5 .

- $0,5 \mathrm{~mL}$ do extrato da enzima

A mistura foi incubada durante 1 hora, a $30^{\circ} \mathrm{C}$. A reação foi interrompida pela adição de $1 \mathrm{~mL}$ de $\mathrm{NaOH} 1 \mathrm{~N}$, acrescentando-se $0,5 \mathrm{~mL}$ de tampão Macllvaine $50 \mathrm{mmol}$ $\mathrm{L}^{-1}, \mathrm{pH} 7$ e $1 \mathrm{~mL}$ de $\mathrm{HCl} 1 \mathrm{~N}$, procedendo-se em seguida a reação de coloração com kit Spectroquant da Merck, para dosagem de cianeto em solução, e a leitura da absorvância a $585 \eta \mathrm{m}$.

\subsection{Potencial cianogênico ( $\mathrm{HCN}-\mathrm{p})$ de clones de copa de seringueira}

$\mathrm{O}$ potencial cianogênico foi determinado em folhas jovens (estádio $\mathrm{C}$ ) e maduras (penúltimo lançamento) do clone de painel IPA 1 ( $H$. brasiliensis); dos clones de copa compatível com esse clone: IAN 6158 (H. brasiliensis x H. benthamiana), Fx 985 ( $H$. brasiliensis) e CPAA C 65 (H. nitida); e dos clones de copa incompativel: CPAA C 06 (H. pauciflora), CPAA C 13, CPAA C 14 (H. pauciflora $\times$ H. guianensis var marginata), CPAA C 50 (H. pauciflora x H. rigidifolia), CBA 1 e CNS G 124 ( $H$. pauciflora). As determinações foram realizadas em três repetições, sendo cada planta uma repetição. Os resultados foram submetidos à análise de variância (Teste F) e de comparação de contrastes entre médias através do teste de Tukey a $1 \%$ de probalidade. 


\subsubsection{Extração da linamarase das folhas de seringueira}

Para liberação total do cianeto, na dosagem do HCN-p das folhas, foi adicionado ao meio de incubação $\beta$-glicosidase extraída de folhas de seringueira. $O$ método de extração utilizado foi adaptado de Selmar (1986) e Lieberei (1986).

Folhas de seringueira no estádio $\mathrm{B}$ e $\mathrm{C}$ dos clones IPA 1 e CPAA C 06, que juntas pesaram $47 \mathrm{~g}$, foram picadas e, em seguida, homogeneizadas em liqüidificador durante 2 minutos com a adição de $300 \mathrm{~mL}$ de solução tampão de fosfato $\left(10 \mathrm{mmol} \mathrm{L}{ }^{-1}\right.$ da relação 2:1 $\mathrm{Na}_{2} \mathrm{HPO}_{4} / \mathrm{NaH}_{2} \mathrm{PO}_{4}$ ), $\mathrm{pH}$ 6,5. O homogeneizado foi filtrado em 4 camadas de tecido de algodão e depois centrifugado a $30.000 \mathrm{~g}$, durante uma hora e temperatura variando de zero a seis graus centígrados.

Ao sobrenadante, foi acrescentado sulfato de amônio moído em pó fino até atingir $20 \%$ da saturação ( $8,6 \mathrm{~g}$ de sulfato de amônio para cada $100 \mathrm{~mL}$ de solução). Uma nova centrifugação foi realizada a $20.000 \mathrm{~g}$, por 30 minutos e mesma condição de temperatura, para precipitação de outras proteínas, que não a $\beta$-glicosidase. Foi acrescentado sulfato de amônio ao novo sobrenadante, até completar $80 \%$ da saturação (25,8 g de sulfato para cada $100 \mathrm{~mL}$ de solução), a fim de precipitar o restante das proteínas contendo a enzima, deixando-se em repouso na geladeira por aproximadamente 24 horas. Passado esse período, realizou-se nova centrifugação, nas mesmas condições anteriores. O sobrenadante foi então descartado e o precipitado ressuspenso com adição de $20 \mathrm{~mL}$ de tampão de fosfato.

A dessalinização parcial da proteína foi obtida lavando-se a ressuspensão com tampão de fosfato, $\mathrm{pH} 6,5,10 \mathrm{mmol} \mathrm{L}^{-1}$, com filtração em membrana Milipore, tipo PTGC, sob pressão constante de 2,5 bárias. O tampão de fosfato foi adicionado em parcelas de $50 \mathrm{~mL}$, a cada lavagem, consumindo-se um total de $300 \mathrm{~mL}$. Após a adição dos últimos $50 \mathrm{~mL}$ de tampão, a filtração sob pressão continuou até atingir o volume de $15 \mathrm{~mL}$. Esse procedimento foi adotado em substituição à cromatografia em coluna de gel de Sephadex G 150, utilizada por vários autores e cujo procedimento mostrou-se muito demorado, obtendo-se enzima com atividade inferior à mencionada por Lieberei (1986). 
A "lavagem" da proteína com o tampão permitiu também a eliminação do cianeto presente nas folhas de seringueira, cujo conteúdo foi determinado utilizando-se procedimento descrito no item 3.6.2.

\subsubsection{Determinação da atividade da linamarase}

A atividade da $\beta$-glicosidase foi determinada no meio de incubação com $\mathrm{p}$ nitrofenilglucopiranosídeo, segundo Selmar (1986), medida pela liberação de pnitrofenol (p-NP) no meio de incubação, com a seguinte composição inicial:

- $1 \mathrm{~mL}$ de solução a $10 \mathrm{mmol} \mathrm{L}^{-1}$ de p-nitrofenilgulcopiranosídeo diluído em tampão de acetato, $0,1 \mathrm{~mol} \mathrm{~L}^{-1}, \mathrm{pH} 5,5$;

- $3,9 \mathrm{~mL}$ de tampão de acetato;

- $0,1 \mathrm{~mL}$ de solução de $\beta$-glicosidase.

- Total de $5 \mathrm{~mL}$.

O tempo de incubação foi de 10 minutos a temperatura ambiente. Após incubação, transferiu-se $0,5 \mathrm{~mL}$ da mistura para frasco contendo $1 \mathrm{~mL}$ de $\mathrm{NaCO}_{3}, 0,5$ mol L ${ }^{-1}$, pré-resfriado, e $2,5 \mathrm{~mL}$ de água destilada. A leitura da absorvância foi efetuada a 400 ๆm, e o cálculo da quantidade de p-nitrofenol liberado por minuto, com base na curva padrão de p-nitrofenol, descrita no item 3.8.2.

A atividade encontrada foi de $0,2 \mu \mathrm{mol}$ p-NP min $^{-1}$, cujo resultado é praticamente igual ao valor de $0,22 \mu \mathrm{mol} \mathrm{min}^{-1}$ apresentado por Lieberei (1986) para $\beta$-glicosidase também extraída de folha jovem de seringueira e semi-purificada em coluna de gel de Sephadex G 150.

Para maior segurança quanto ao desempenho da enzima extraída, fez-se um teste de sua capacidade de hidrólise com solução de linamarina na concentração de $0,238 \mathrm{mg}$ $\mathrm{mL}^{-1}$, correspondendo a $25,04 \mathrm{mg} \mathrm{L}^{-1}$ de $\mathrm{CN}^{-}$. Como meio de incubação foram utilizados $0,1 \mathrm{~mL}$ de solução de linamarina, $0,45 \mathrm{~mL}$ de $\mathrm{NaH}_{2} \mathrm{PO}_{4}\left(0,067 \mathrm{~mol} \mathrm{~L}^{-1}\right)$ e $0,1 \mathrm{~mL}$ da enzima. $O$ período de incubação foi de 20 minutos.

Passado o tempo de incubação, acrescentou-se $0,6 \mathrm{~mL}$ de $\mathrm{NaOH}, 0,2 \mathrm{~mol} \mathrm{~L}^{-1} \mathrm{e}$ $3,85 \mathrm{~mL}$ de água destilada. Em seguida foram adicionados os reagente do kit 
Spectroquant da Merck para determinação de cianeto em soluções, nas quantidades adequadas para amostras de $5 \mathrm{~mL}$.

A leitura da absorvância a $585 \eta \mathrm{m}$ foi feita cinco minutos após a adição dos reagentes. $O$ cálculo da quantidade de cianeto liberado foi feito com base em curva padrão de cianeto, nas concentrações em $\mathrm{mg} \mathrm{L}^{-1}$ de 0,$1 ; 0,2 ; 0,3 ; 0,4$ e 0,5 , obtendo-se o valor esperado com a hidrólise completa do glicosídeo pela ação da enzima adicionada ao meio de reação.

\subsubsection{Determinação do HCN-p em folhas jovens e maduras}

\subsubsection{Preparo da amostra}

Para as determinações de $\mathrm{HCN}$-p foram pesados separadamente $1 \mathrm{~g}$ de folhas jovens no estádio $\mathrm{C}$ de desenvolvimento e de folhas maduras do penúltimo lançamento, para cada clone avaliado. Após a pesagem as amostras foram picadas e moídas em gral com pistilo pré resfriados com a adição de $4 \mathrm{~mL}$ de $\mathrm{Na}_{2} \mathrm{HPO}_{4}\left(0,067 \mathrm{~mol} \mathrm{~L}^{-1}\right)$ também pré-resfriado, sendo que às folhas maduras acrescentou-se ainda $500 \mathrm{mg}$ de areia lavada, como para a determinação de HCN-p na casca do caule. O homogeneizado obtido foi levado a centrifugar nas condições já descritas no item 3.5.1.

Com alguns clones houve necessidade de diluição, adicionando-se ao sobrenadante $\mathrm{Na}_{2} \mathrm{HPO}_{4}\left(0,067 \mathrm{~mol} \mathrm{~L}{ }^{-1}\right)$, na proporção de $1: 10$, devido ao $\mathrm{HCN}$-p muito alto, para permitir leituras dentro da faixa da curva padrão.

Para o branco foi utilizado $0,05 \mathrm{~mL}$ do sobrenadante adicionado de $0,45 \mathrm{~mL}$ de $\mathrm{NaH}_{2} \mathrm{PO}_{4}$, completando-se o volume para $5 \mathrm{~mL}$ com água destilada.

\subsubsection{Determinação do HCN-p}

Para a incubação foram transferidos $0,05 \mathrm{~mL}$ do sobrenadante para os frascos de reação, procedendo-se a seguir como na descrição do teste da enzima com solução de linamarina (item 3.11.1.1) com exceção do volume de água destilada adicionada, que neste caso foi de $3,8 \mathrm{~mL}$. 


\section{RESULTADOS E DISCUSSÃO}

\subsection{Resposta à aplicação de $\mathrm{KCN}$ em dose única}

Comparado ao clone IPA 1, o Fx 3864 apresentou tolerância extremamente alta ao $\mathrm{KCN}$, aplicado em diferentes concentrações, em dose única de $2 \mathrm{~mL}$ de solução, tendo o Fx 4098 mostrado comportamento intermediário (Tabela 1). A concentração mais alta de KCN sem nenhum efeito sobre a exsudação do látex do Fx 3864 (20 mg $\mathrm{L}^{-1}$ ), com cinco dias após a aplicação, foi 625 vezes maior que a concentração mais baixa $\left(0,032 \mathrm{mg} \mathrm{L}^{-1}\right)$ em que deixou de haver escoamento de látex no IPA 1 , em toda a extensão do caule tratado, com dois dias após a aplicação. $O$ volume de solução aplicada $(2 \mathrm{~mL})$ estava totalmente absorvido no dia seguinte ao da aplicação, em todas as concentrações de $\mathrm{KCN}$, exceto no IPA 1, em que houve redução do volume absorvido, progressivamente, a partir da concentração de $4 \mathrm{mg} \mathrm{L}^{-1}$. Mesmo com cinco dias após o início do tratamento, o efeito sobre o escoamento do látex do IPA 1 , com a concentração mais alta $\left(100 \mathrm{mg} \mathrm{L}^{-1}\right)$, ainda não era completo, o que deve estar relacionado com a menor absorção da solução. Apenas no IPA 1 houve efeito da concentração mais baixa $\left(0,0064 \mathrm{mg} \mathrm{L}^{-1}\right)$, com cinco dias, afetando, porém, pequena extensão do caule. $\mathrm{O}$ mesmo grau de resposta foi apresentado pelo Fx 3864, com cinco dias, porém, com a concentração mais alta.

Em todas as concentrações de $\mathrm{KCN}$, observou-se nos três clones uma faixa, de no máximo $0,5 \mathrm{~cm}$ de largura, de casca necrosada, a partir do topo cortado, próxima do tubo com a solução. Abaixo dessa faixa, mais larga no IPA 1, a casca apresentava aspecto externo sadio. Não houve, portanto reprodução integral dos sintomas verificados com as copas enxertadas incompatíveis com o IPA 1, em que há necrose completa da casca do caule, em certa extensão, abaixo da união do enxerto. A ocorrência de necrose apenas no 
topo cortado dos ramos laterais sugere que houve bloqueio da translocação de $\mathrm{KCN}$, como relatado por Gur (1957).

A adição de sacarose à solução de KCN não resultou em aumento da extenção da necrose ao longo do caule.

Tabela 1. Efeito de doses de $\mathrm{KCN}$, em uma só aplicação, sobre o escoamento do látex no caule.

\begin{tabular}{|c|c|c|c|c|c|c|c|c|c|}
\hline \multirow{3}{*}{$\begin{array}{l}\mathrm{KCN} \\
\mathrm{mg} \mathrm{L}^{-1}\end{array}$} & \multicolumn{9}{|c|}{ Dias após a aplicação } \\
\hline & \multicolumn{3}{|c|}{1} & \multicolumn{3}{|c|}{2} & \multicolumn{3}{|c|}{5} \\
\hline & IPA 1 & Fx 4098 & Fx 3864 & IPA 1 & Fx 4098 & Fx 3864 & IPA 1 & Fx 4098 & Fx 3864 \\
\hline$A-0,0064$ & 0 & 0 & 0 & 1 & 0 & 0 & 1 & 0 & 0 \\
\hline B - $\mathbf{0 , 0 3 2}$ & 2 & 0 & 0 & 3 & 0 & 0 & 3 & 0 & 0 \\
\hline$C-0,16$ & 2 & 0 & 0 & 3 & 0 & 0 & 3 & 0 & 0 \\
\hline D $-\mathbf{0 , 8}$ & 2 & 0 & 0 & 3 & 0 & 0 & 3 & 0 & 0 \\
\hline$E-4,0$ & 2 & 0 & 0 & 3 & 1 & 0 & 3 & 1 & 0 \\
\hline F - 20,0 & 2 & 1 & 0 & 2 & 2 & 0 & 3 & 2 & 0 \\
\hline$G-100,0$ & 1 & 1 & 0 & 2 & 2 & 0 & 2 & 3 & 1 \\
\hline \multicolumn{10}{|l|}{ 0- Exsud } \\
\hline 1- Sem e & $x$ & 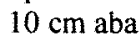 & do top & & & & & & \\
\hline 2- Sem e & dação a & $30 \mathrm{~cm}$ aba & xo do topo & & & & & & \\
\hline
\end{tabular}

A inspeção ao microscópio, dos cortes a mão livre, confirmou a presença de borracha (látex coagulado) nos laticíferos das áreas de casca em que deixou de haver exsudação de látex. Observou-se também a ocorrência de células do parênquima com inclusões de tanino. No IPA 1, a partir da concentração de $0,16 \mathrm{mg} \mathrm{L}^{-1}$ de $\mathrm{KCN}$ e no Fx 4098, a partir de $5 \mathrm{mg} \mathrm{L}^{-1}$, foi observada uma camada de células necróticas, com acúmulo de substâncias escuras, na parte intermediária entre a epiderme e o câmbio, porém sem sintomas externos visiveis. Tal fato indica que, apesar do provável bloqueio da absorção, deve ter ocorrido translocação de parte do $\mathrm{KCN}$, o que conduziu ao teste com aplicação contínua da solução, nos tubos plásticos ajustados ao topo cortado, com o objetivo de induzir necrose do caule do IPA 1, semelhante à das combinações com copas incompativeis 


\subsection{Resposta à aplicação contínua de $\mathrm{KCN}$}

Com aplicação contínua das soluções com diferentes concentrações de $\mathrm{KCN}$, em ramos laterais idênticos aos da aplicação em dose única, a partir do segundo dia a absorção da solução tornou-se muito lenta e foi praticamente nula a partir do terceiro dia.

Em face desse aparente impedimento do transporte do $\mathrm{KCN}$, os resultados da aplicação contínua diferiram muito pouco dos da aplicação em dose única, registrandose apenas que no Fx 4098 com concentração de $20 \mathrm{mg} \mathrm{L}^{-1}$, a necrose estendeu-se por cerca de $5 \mathrm{~cm}$ abaixo do topo. Tais resultados mostraram a impossibilidade de reprodução da necrose verificada na incompatibilidade de copas enxertadas sobre o IPA 1, devida a pouca mobilidade do KCN na casca do caule dos ramos laterais.

Cerca de 45 dias após os tratamentos houve brotações de gemas ao longo dos caules tratados e recuperação parcial do escoamento do látex, no IPA 1 e no Fx 4098, o que pode ser atribuído à reativação do câmbio.

\subsection{Resposta à aplicação de linamarina}

O diglicosídeo linustatina, sendo a forma natural de transporte (Selmar, 1993) seria o composto ideal para o teste dos efeitos sobre o caule, na tentativa de reprodução dos sintomas de incompatibilidade. Trata-se, entretanto, de composto não disponível comercialmente.

Os testes foram efetuados com linamarina, que, embora tenha o inconveniente da hidrólise mais rápida que a da linustatina, deveria corresponder a uma forma com maior mobilidade que o $\mathrm{KCN}$.

\subsubsection{Marcha de absorção das soluções}

Nos primeiros dois dias, após a aplicação das soluções, houve absorção completa dos $3 \mathrm{~mL}$ aplicados diariamente, exceto na dose de $125 \mathrm{mg} \mathrm{L}^{-1}$ no IPA 1 . No terceiro dia, houve redução, para cerca da metade do volume aplicado e quase ausência de absorção no IPA 1, com 25 e $125 \mathrm{mg} \mathrm{L}^{-1}$. No quinto dia, praticamente não houve absorção nos três clones, nas concentrações a partir de $5 \mathrm{mg} \mathrm{L}^{-1}$, enquanto a absorção do controle com água destilada mais DMSO 0,05\%, foi, aproximadamente, de 1,2 mL, o 
que mostra que mesmo sem exposição ao $\mathrm{HCN}$, houve redução, embora mais lenta. da capacidade de transporte do floema, provavelmente apenas mais próximo à superficie cortada.

A marcha da absorção das soluções com linamarina mostra que o sistema de transporte do floema manteve-se funcional por mais tempo que com a exposição direta ao cianeto e destaca, novamente, o IPA 1 como mais sensível, tendo reduzido a absorção em prazo mais curto. Os resultados sugerem, por outro lado, que a hidrólise da linamarina deve ter sido gradual, mesmo no IPA 1, permitindo o transporte, pelo menos, de parte desse glicosídeo, em maior extensão que a do $\mathrm{KCN}$, ao longo do caule, a julgar pelos efeitos sobre o escoamento e indução de necrose, relatados a seguir.

\subsubsection{Efeito sobre o escoamento do látex e indução de necrose}

Os resultados mostram claramente que a coagulação do látex nos laticíferos precede o aparecimento da necrose da casca visível externamente (Tabela 2), tal como acontece quando copas incompatíveis são enxertadas sobre o IPA 1, porém em intervalos mais curtos.

Com dois dias após o início do tratamento, deixou de haver escoamento do látex no IPA 1, em todo o comprimento do ramo lateral tratado, exceto na concentração mais baixa e na mais alta. Certamente, o menor efeito da concentração mais alta, com dois dias no IPA 1, foi devido ao bloqueio da translocação já mencionado, o que implica em maior concentração de $\mathrm{HCN}$ livre nesse clone, com a aplicação de linamarina. Com quatro dias verificou-se maior extensão do caule sem escoamento de látex, no IPA 1, com a dose mais baixa, ocorrendo o mesmo com a dose mais alta, no sexto dia (Tabela 2).

Como na aplicação de $\mathrm{KCN}$, a ausência de escoamento de látex com aplicação de linamarina manifestou-se mais cedo e de modo mais severo no IPA 1 que no Fx 4098, enquanto o Fx 3864 não foi afetado. No Fx 4098 as duas doses mais baixas também não causaram coagulação do látex. Esse efeito foi apenas parcial, com a concentração de 1 $\mathrm{mg} \mathrm{L}^{-1}$, ainda não atingindo todo o comprimento do ramo lateral tratado com $5 \mathrm{mg} \mathrm{L}^{-1}$. Nas duas concentrações mais altas observou-se ausência de escoamento em todo o comprimento do ramo lateral. 
Tabela 2. Efeito de doses de linamarina sobre o escoamento do látex e indução de necrose em toda a espessura da casca, aplicadas durante cinco dias consecutivos nos clones IPA 1, Fx 4098 e Fx 3864.

\begin{tabular}{|c|c|c|c|c|c|c|c|c|c|c|c|c|}
\hline \multirow{3}{*}{$\underset{\text { mg L L }^{-1}}{\text { Linamarna }}$} & \multicolumn{12}{|c|}{ Dias após a aplicação } \\
\hline & \multicolumn{3}{|c|}{2} & \multicolumn{3}{|c|}{4} & \multicolumn{3}{|c|}{6} & \multicolumn{3}{|c|}{10} \\
\hline & IPA 1 & Fx 4098 & Fx 3864 & IPA 1 & FX 4098 & Fx 3864 & IPA 1 & Fx 4098 & Fx 3864 & IPA 1 & Fx 4098 & Fx 3864 \\
\hline \multirow[b]{2}{*}{ A- 0,04} & - & - & - & - & - & - & $\mathrm{N}$ & - & - & NNN & - & - \\
\hline & 1 & 0 & 0 & 3 & 0 & 0 & 3 & 0 & 0 & 3 & 0 & 0 \\
\hline \multirow[b]{2}{*}{ B - 0,2} & - & - & - & - & - & - & NN & - & - & NNN & - & - \\
\hline & 3 & 0 & 0 & 3 & 0 & 0 & 3 & 0 & 0 & 3 & 0 & 0 \\
\hline \multirow[b]{2}{*}{$C-1,0$} & - & - & - & - & - & - & NN & 一 & - & NNN & - & 一 \\
\hline & 3 & 0 & 0 & 3 & 0 & 0 & 3 & 1 & 0 & 3 & 1 & 0 \\
\hline \multirow[b]{2}{*}{$D-5,0$} & - & - & - & - & - & - & NN & - & - & NNN & - & - \\
\hline & 3 & 0 & 0 & 3 & 2 & 0 & 3 & 2 & 0 & 3 & 2 & 0 \\
\hline \multirow[b]{2}{*}{$E-25,0$} & - & - & - & - & - & - & $\mathrm{N}$ & - & - & NN & NN & - \\
\hline & 2 & 0 & 0 & 3 & 3 & 0 & 3 & 3 & 0 & 3 & 3 & 0 \\
\hline \multirow[b]{2}{*}{$F-125,0$} & - & - & - & - & - & - & $\mathrm{N}$ & - & - & NN & NN & - \\
\hline & 1 & 1 & 0 & 2 & 2 & 0 & 3 & 3 & 0 & 3 & 3 & 0 \\
\hline \multirow{2}{*}{$\begin{array}{l}\text { DMSO } \\
(0,05 \%)\end{array}$} & - & - & - & - & - & - & - & - & - & - & - & - \\
\hline & 0 & 0 & 0 & 0 & 0 & 0 & 0 & 0 & 0 & 0 & 0 & 0 \\
\hline \multirow{5}{*}{$\begin{array}{l}\overline{-}: \\
\mathrm{N}: \\
\mathrm{NN}: \\
\mathrm{NNN}:\end{array}$} & \multirow{2}{*}{\multicolumn{6}{|c|}{ Ausência de necrose }} & \multicolumn{6}{|l|}{ : Es } \\
\hline & & & & & & & \multirow{2}{*}{\multicolumn{6}{|c|}{ : Sem escoamento até $30 \mathrm{~cm} \mathrm{ab}$}} \\
\hline & \multicolumn{6}{|c|}{ Necrose até $30 \mathrm{~cm}$ abaixo do topo } & & & & & & \\
\hline & \multirow{2}{*}{\multicolumn{6}{|c|}{$\begin{array}{l}\text { Necrose em } \\
80 \mathrm{~cm})\end{array}$}} & \multirow{2}{*}{\multicolumn{6}{|c|}{$\begin{array}{l}\text { Sem escoamento até } 30 \mathrm{~cm} \text { abaixo do topo } \\
\text { (60 a } 80 \mathrm{~cm})\end{array}$}} \\
\hline & & & & & & & & & & & & \\
\hline
\end{tabular}

Entre a coagulação do látex e os sintomas externamente visíveis de necrose da casca, houve um intervalo de quatro dias no IPA 1 e de seis dias no Fx 4098, o que contrasta com o período de até dois meses, entre o início da redução do escoamento do látex e os primeiros sinais externos de necrose da casca do IPA 1, com copas enxertadas incompatíveis. Tal fato, em princípio, deve ser atribuído à rapidez da liberação de HCN pela linamarina, sob ação da $\beta$-glicosidase situada nas paredes das células.

A necrose da casca do caule, verificada aos dez dias, no Fx 4098, foi provocada apenas pelas duas concentrações mais altas de linamarina, com a necrose estendendo-se entre 10 e $30 \mathrm{~cm}$ abaixo do topo cortado. No Fx 3864 nenhuma das concentrações de linamarina testadas causou necrose da casca, o que é coerente com a ausência de efeito sobre o escoamento do látex. 
Verifica-se assim que o Fx 3864 mostrou-se insensivel às doses de $\mathrm{KCN}$ e de linamarina, o que poderia ser atribuído a maior imobilidade do $\mathrm{KCN}$ e da linamarina nesse clone, mas, nesse caso, teria ocorrido necrose nítida próximo à superfície do topo cortado, em contato imediato com as soluções. A hipótese alternativa, de maior capacidade de fixação do HCN no Fx 3864 e, um pouco menor, no Fx 4098, comparada a capacidade muito baixa de desintoxicação do IPA 1, mostrou-se correta, a julgar pelos níveis de atividade da $\beta$-cianoalaninasintase encontrada nesses três clones (ver item 4.6). Para tornar possível a interpretação das diferenças entre os três clones aos tratamentos com $\mathrm{KCN}$ e linamarina, bem como o do mecanismo de incompatibilidade, foram determinadas, além da $\beta$-cianoalaninasintase, as atividades da $\beta$-glicosidase e da $\beta$ diglicosidase, cujas relações com as respostas ao $\mathrm{KCN}$ e à linamarina serão discutidas na apresentação dos resultados do estudo dessas enzimas.

\subsection{Ação do cianeto na coagulação do látex "in vitro"}

Os resultados da Tabela 3 mostram que a coagulação do látex nos laticíferos do IPA 1, em prazo mais curto de tratamento com as soluções de diferentes concentrações de $\mathrm{KCN}$ ou linamarina aplicadas no caule, que dos outros dois clones, não é devida a menor estabilidade do látex do IPA 1 ao cianeto. Verificou-se pelo contrário que foi necessário um volume maior de solução de $\mathrm{KCN}, 300 \mathrm{mmol} \mathrm{L}^{-1}$, para a coagulação do látex do IPA 1.

Tabela 3. Volume da solução de $\mathrm{KCN}, 300 \mathrm{mmol} \mathrm{L}^{-1}$, consumido na coagulação de 20 $\mathrm{mL}$ de látex

\begin{tabular}{lc}
\hline Clones & KCN $(\mathbf{m L})$ \\
\hline Fx 4098 & 1,2 \\
Fx 3864 & 1,7 \\
IPA 1 & 2,1 \\
\hline
\end{tabular}




\subsection{Concentração de $\mathrm{HCN}$ livre nos caules submetidos a diferentes tempos de exposição à solução de linamarina}

Os efeitos da aplicação de $\mathrm{KCN}$ e de linamarina, sobre o escoamento do látex e indução de necrose, indicam maior concentração de HCN livre na casca do caule do IPA 1, a qual pode ser determinada se a extração das amostras for efetuada com ácido ortofosfórico, que corresponde a $\mathrm{pH}$ muito baixo, na faixa de inativação da $\beta$-glicosidase (Cooke, 1978), ou a nível muito baixo de atividade dessa enzima, de modo a não interferir significativamente no teor de $\mathrm{HCN}$ livre existente antes da homogeneização das amostras. $\mathrm{O} \mathrm{pH}$ dos extratos com $\mathrm{H}_{3} \mathrm{PO}_{4}, 0,067 \mathrm{~mol} \mathrm{~L}^{-1}$ foi de 2,81 .

Foi realizada a comparação entre os clones IPA 1 e Fx 3864, este praticamente não afetado pelos tratamentos com $\mathrm{KCN}$, ou linamarina. Os resultados mostraram-se plenamente coerentes com a previsão, tendo o IPA 1 acumulado teores significativamente mais altos de HCN que o Fx 3864 (Figura 2). Observa-se que houve acúmulo de $\mathrm{HCN}$ no IPA 1 até 12 horas após o início do tratamento (Figura 2). A redução gradativa para teores abaixo dos encontrados no Fx 3864, com 24 horas após o início do tratamento, deve ser atribuída à degeneração dos tecidos da casca pela ação tóxica do cianeto, que inibe a cadeia de transporte eletrônico da respiração normal, sendo a energia metabolicamente disponível, gerada pelo caminho alternativo da respiração resistente ao cianeto, caracterizada na casca da seringueira por Siew \& Shaoqiong (1984), insuficiente para a sintese de compostos complexos ou para a manutenção da integridade das membranas.

No Fx 3864 o teor de HCN livre permaneceu constante durante o periodo das observações, devendo-se, entretanto, considerar a possibilidade de que parte do $\mathrm{HCN}$ liberado seja produto de ação residual da $\beta$-glicosidase, no $\mathrm{pH} 2,81$, conforme a curva de atividade em função do $\mathrm{pH}$, apresentada por Selmar (1986), o mesmo sendo válido para os extratos das amostras de casca do IPA 1. De qualquer modo, o maior teor de HCN livre no IPA 1 está de acordo com as respostas ao KCN e linamarina, considerando-se, por outro lado, que uma atividade alta de $\beta$-cianoalaninasintase nesse clone deveria atuar no sentido de manutenção de baixos teores de $\mathrm{HCN}$ livre. 


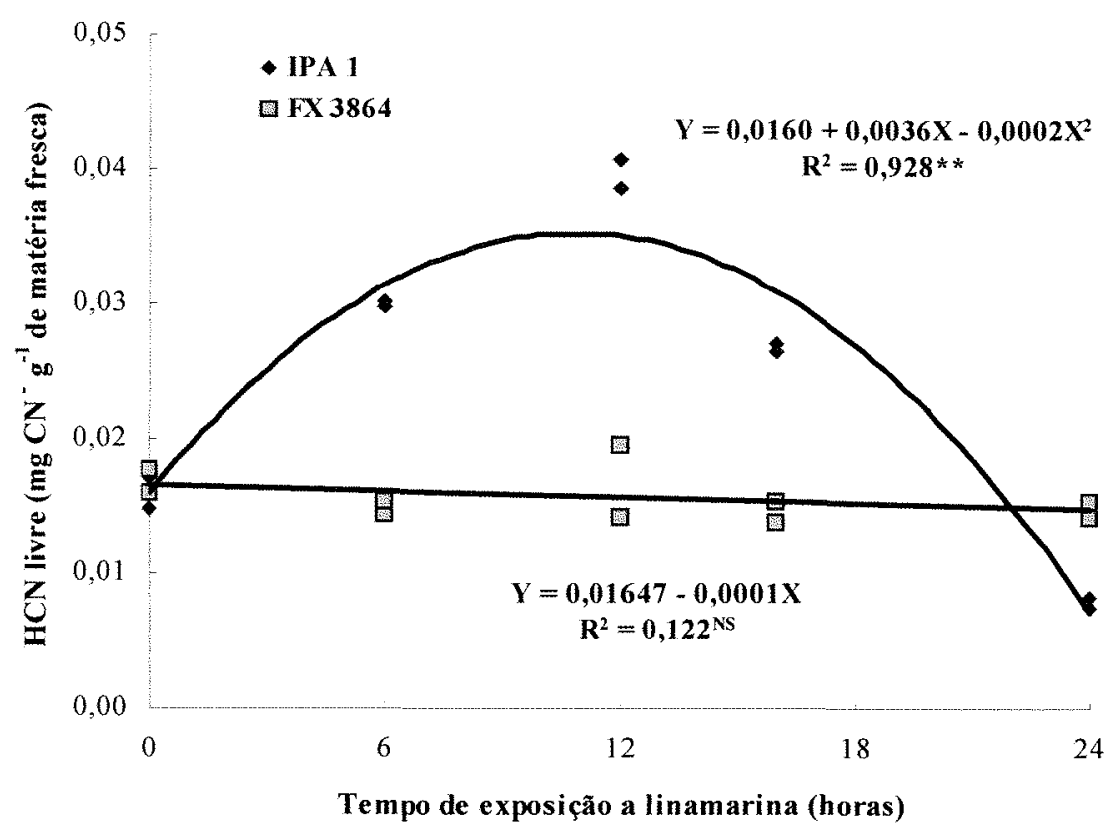

Figura 2. HCN livre na casca do caule dos clones IPA 1 e Fx $3864 \mathrm{em} \mathrm{mg} \mathrm{g}^{-1}$ de matéria fresca, em função do tempo de exposição a dose única de solução de linamarina $\left(6 \mathrm{mg} \mathrm{L}^{-1}\right)$. **Significativo a $1 \%$ de probabilidade pelo teste $\mathrm{F}$ e $\mathrm{NS}_{\text {não significativo. }}$

\subsection{Atividade da $\beta$-cianoalaniansintase ( $\beta$-CAS)}

A atividade da $\beta$-CAS observada no IPA $1\left(0,015 \eta \mathrm{mol} \mathrm{H}_{2} \mathrm{~S} \mathrm{~s}^{-1} \mathrm{~g}^{-1} \pm 0,007\right)$ foi 7 vezes menor quando comparada ao $\mathrm{Fx} 4098\left(0,110 \eta \mathrm{mol} \mathrm{H}_{2} \mathrm{~S} \mathrm{~s}^{-1} \mathrm{~g}^{-1} \pm 0,007\right)$, e 13 vezes menor, quando comparada ao Fx $3864\left(0,196 \eta \mathrm{mol} \mathrm{H}_{2} \mathrm{~S} \mathrm{~s}^{-1} \mathrm{~g}^{-1} \pm 0,007\right)$ (Figura 3). Os valores observados diferiram entre si, pelo teste de Tukey, ao nível de $1 \%$ de probabilidade.

Esses resultados estão de acordo com a hipótese de que no IPA 1 a fixação do cianeto em compostos não cianogênicos é menos eficiente de que nos demais clones testados e coerente com os teores de $\mathrm{HCN}$ livre encontrados nesse clone, com a aplicação de linamarina (Tabela 2), bem como com as respostas observadas, aos tatamentos com $\mathrm{KCN}$ (Tabela 1) e linamarina, em diferentes concentrações. 


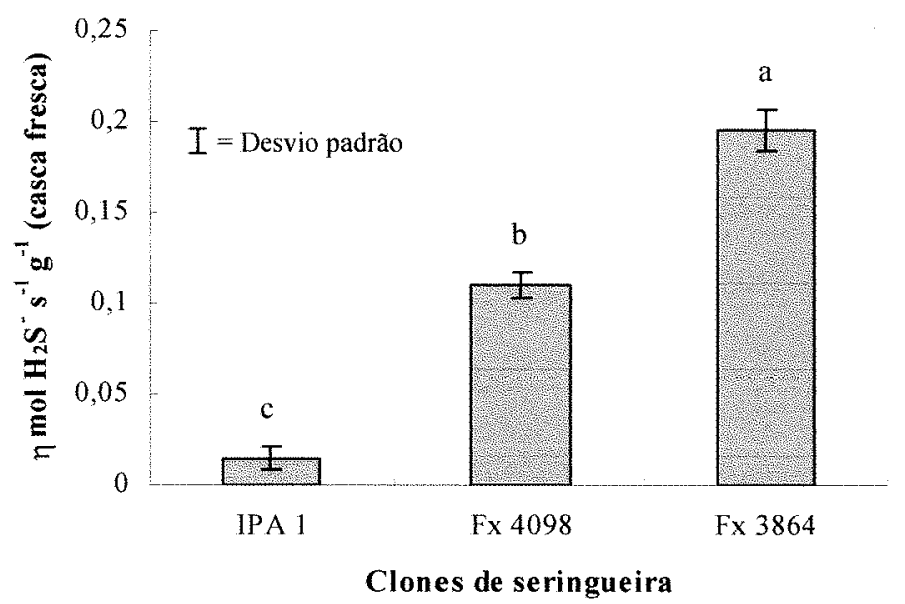

Figura 3. Atividade de $\beta$-CAS na casca do caule dos clones de seringueira IPA 1, Fx 4098 e Fx 3864.

Os valores de atividade de $\beta$-CAS dos clones Fx 3864 e Fx 4098 mostrados na Figura 3 são da mesma ordem de grandeza dos relatados por Umbach (1989) e explicam também as diferenças de resposta ao KCN e à linamarina, entre o Fx 4098 e o Fx 3864. A atividade muito baixa de $\beta$-CAS observada no IPA 1 é um exemplo extremo de variação de atividade dessa enzima em seringueira, encontrada por Umbach (1989), em diferentes espécies de Hevea. A atividade de $\beta$-CAS observada no IPA 1 é equivalente à de espécies não cianogénicas, de acordo com os valores apresentados por Miller \& Conn (1980), sendo tais níveis de atividade suficientes apenas para a fixação de pequena quantidade de HCN liberada na síntese de etileno

\subsection{Atividade da $\beta$-glicosidase (linamarase)}

Os resultados da determinação da atividade da $\beta$-glicosidase são expressos em microgramas de p-nitrofenol ( $\mathrm{p}-\mathrm{NP})$, liberados por grama de casca fresca por minuto. $\mathrm{O}$ clone IPA 1 apresentou atividade de $\beta$-glicosidase na casca do caule na ordem de 7,12 $\mu \mathrm{mol} p$-NP g ${ }^{-1} \min ^{-1} \pm 0,66$, aproximadamente o dobro dos valores observados para os clones Fx $4098\left(3,03 \mu \mathrm{mol}\right.$ p-NP g $\left.{ }^{-1} \min ^{-1} \pm 0,10\right)$ e Fx $3864\left(3,24 \mu \mathrm{mol}\right.$ p-NP g ${ }^{-1} \min ^{-1}$ 
$\pm 0,29$ ) (Figura 4), sendo que estes últimos não diferiram entre si, pelo teste de Tukey, ao nível de $1 \%$ de probabilidade.

Cerca de $17 \%$ da atividade enzimática foi encontrada no filtrado dos extratos dos três clones, o que indica que a membrana utilizada é permeável pelo menos para a forma monomérica da enzima.

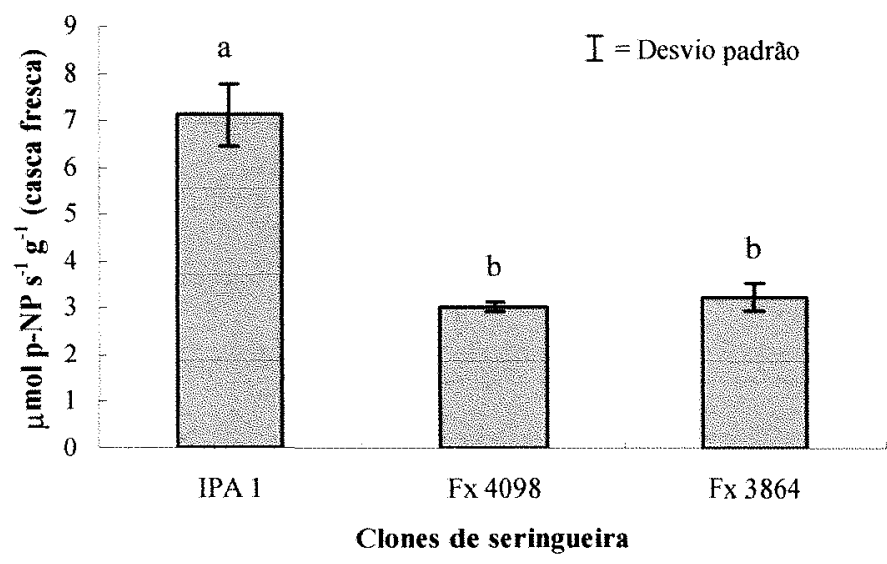

Figura4. Atividade de $\beta$-glicosidase na casca do caule dos clones de seringueira IPA 1, Fx 4098 e Fx 3864.

Os níveis de atividade de $\beta$-glicosidase na casca do caule dos clones estudados comprovam o potencial de hidrólise da linamarina aplicada. A atividade mais alta de $\beta$ glicosidase encontrada no IPA 1 , associada à muito baixa atividade de $\beta$-CAS, são responsáveis pela maior concentração de $\mathrm{HCN}$ livre desse clone, quando tratado com linamarina (Figura 2).

\subsection{Enxertia de clones de copa de baixo potencial cianogênico, no clone IPA 1}

Nos enxertos dos clones considerados de baixo HCN-p, F 4512, PL 22, PUA 5 e PUA 9, de acordo com os valores apresentados por Lieberei (1986), as brotações desenvolveram-se normalmente e não houve redução do escoamento do látex ou 
qualquer outro sintoma de incompatibilidade por translocação no IPA 1, abaixo dos enxertos em crescimento (Figura 5-a e 5-b).

Os enxertos do clone CPAA C 13, inicialmente apresentaram aspecto sadio e vigoroso (Figura 6-a), superando em alguns casos os clones de baixo HCN-p, porém, já a partir do segundo lançamento do enxerto, deixou de escoar látex no IPA 1, inicialmente cerca de $10 \mathrm{~cm}$ abaixo da placa do enxerto e posteriormente até no caule principal decapitado, com cerca de $3 \mathrm{~cm}$ de diâmetro.
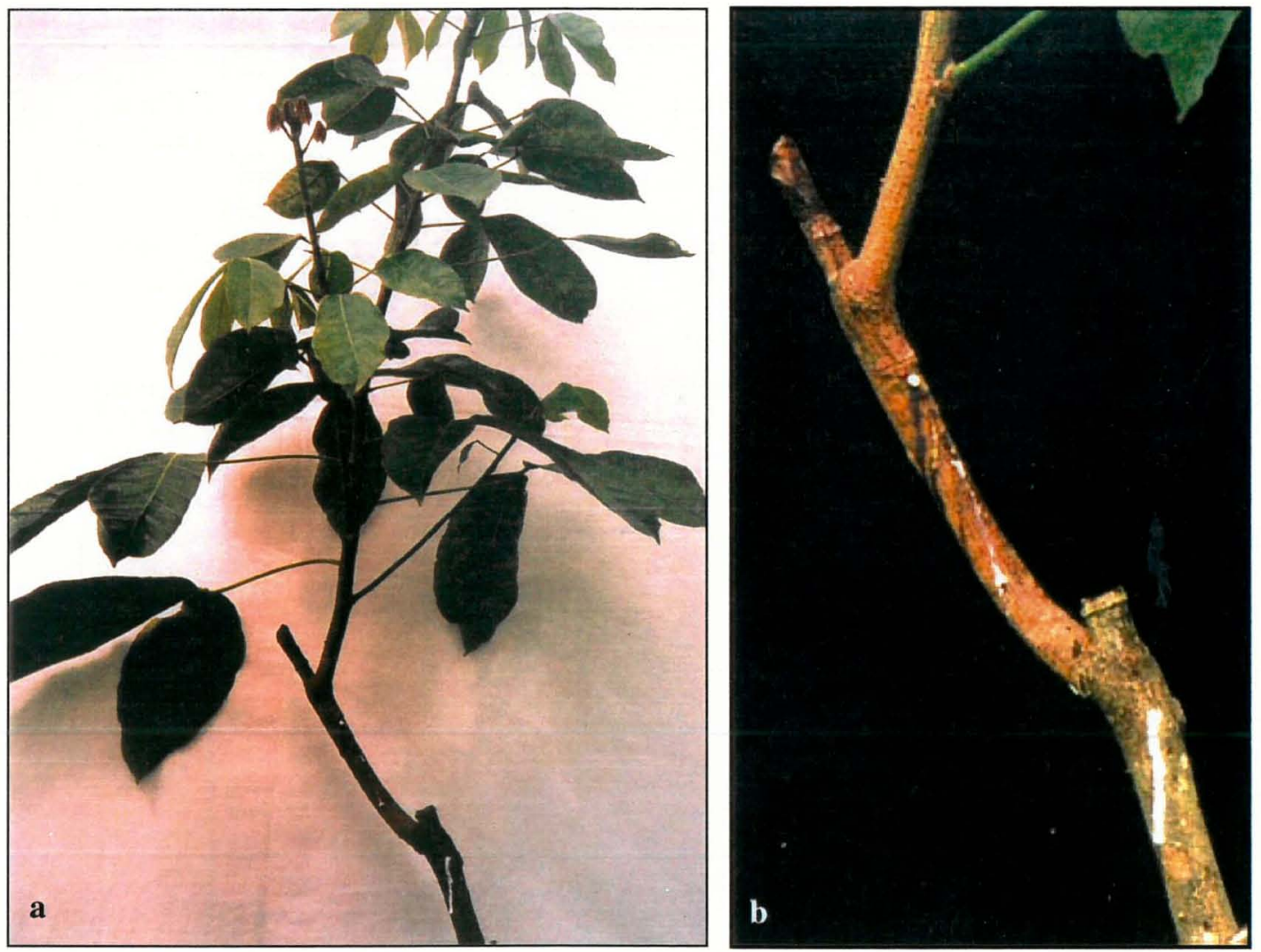

Figura 5. a) Clone de copa Fx 4512 aos seis meses após enxertia em ramo lateral de planta de IPA 1 de jardim clonal, apresentando desenvolvimento normal; b) Detalhe do caule de IPA 1, abaixo do ponto de enxertia, verificando-se escoamento de látex e ausência de necrose. 
No início do terceiro lançamento, passou a ser verificada a necrose da casca do ramo lateral enxertado, a partir das proximidades da placa de enxerto, estendendo-se para baixo até o caule principal. As folhas do enxerto tornaram-se cloróticas, murcharam e em seguida apresentaram secamento progressivo (Figura 6-b), sete dias após a necrose da casca ter atingido um anelamento completo (Figura 6-c).

Esses sintomas reproduzem o mesmo quadro, descrito na Introdução, quando se observou a incompatibilidade por translocação pela primeira vez em Hevea.
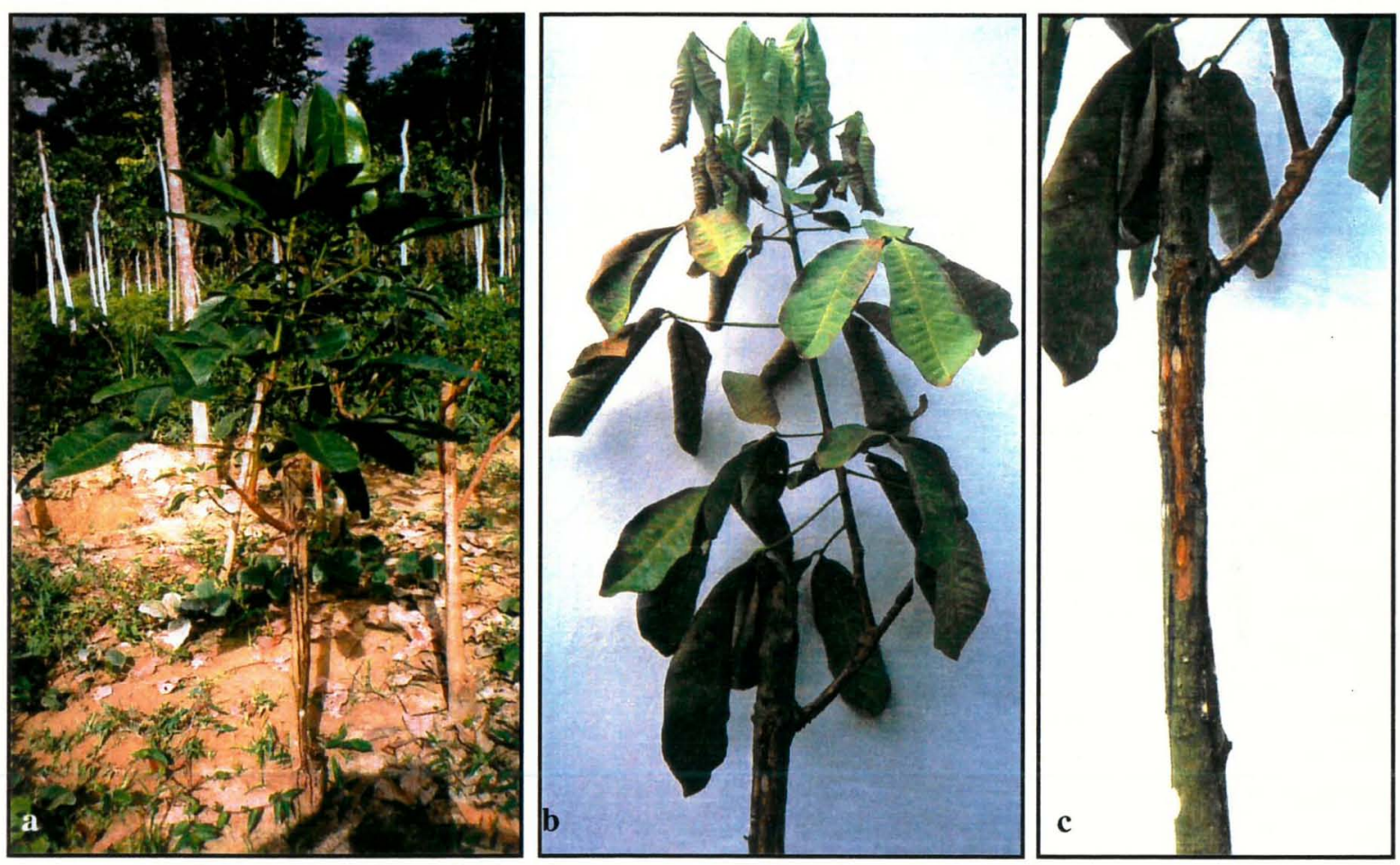

Figura 6. a) Clone de copa CPAA C 13 aos quatro meses após enxertia em ramo lateral de planta de IPA 1 de jardim clonal; apresentando aspecto vigoroso; b) $\mathrm{O}$ mesmo clone de copa, aos 6 meses após enxertia, apresentando folhas secas e quebradiças; c) Detalhe do caule do IPA 1, abaixo do ponto de enxertia, apresentando necrose em ampla extensão

Em cortes da casca do caule foi também verificada a coagulação do látex nos laticíferos e a presença de células com inclusão de tanino. No tecido necrótico acumula- 
se uma substância escura, semelhante à descrita na síndrome do secamento de painel de sangria (Faÿ \& Hébant, 1980). Tais sintomas de incompatibilidade, observados mais detidamente que nas primeiras observações de sua ocorrência, são portanto idênticos aos produzidos pela aplicação de linamarina, e, em parte, pela aplicação de $\mathrm{KCN}$, exceto quanto ao intervalo entre a coagulação do látex nos laticíferos e o aparecimento da necrose em toda a espessura da casca.

\subsection{Atividade da $\beta$-diglicosidase (linustatinase)}

A atividade da $\beta$-diglicosidase na casca do caule do IPA $1\left(2,620 \eta \mathrm{mol} \mathrm{CN}^{-1}\right.$ hora $^{-1} \mathrm{~g}^{-1} \pm 0,190$ ) foi cerca de 4 vezes maior aos valores obtidos para os clones Fx 4098 $\left(0,563 \eta\right.$ mol $\mathrm{CN}^{-1}$ hora $\left.^{-1} \mathrm{~g}^{-1} \pm 0,078\right)$ e Fx $3864\left(0,528 \eta \mathrm{mol} \mathrm{CN}^{-1}\right.$ hora $\left.^{-1} \mathrm{~g}^{-1} \pm 0,087\right)$ (Figura 7), sendo que estes últimos não diferiram entre si, pelo teste de Tukey, ao nível de $1 \%$ de probabilidade.

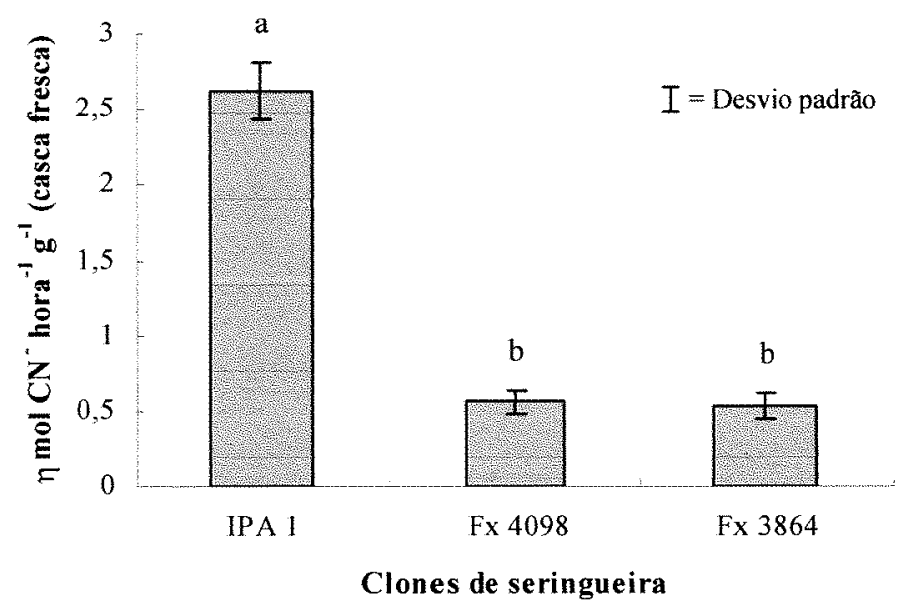

Figura 7. Atividade de $\beta$-diglicosidase na casca do caule dos clones de seringueira IPA 1, Fx 4098 e Fx 3864.

A atividade muito mais baixa da $\beta$-diglicosidase que da $\beta$-glicosidase, na casca do caule, bem como o provável transporte contínuo de linustatina em baixa concentração, em período prolongado, das folhas das copas enxertadas para o caule do 
IPA 1, explica o intervalo, de até dois meses, entre a coagulação do látex e o aparecimento da necrose no caule do IPA 1 enxertado com copa incompatível, e de apenas quatro a seis dias com a aplicação de linamarina.

A atividade da $\beta$-diglicosidase mais alta no IPA 1 ajusta-se a hipótese da incompatibilidade dos enxertos de copa causados por cianogênese

\subsection{Potencial cianogênico de clones de copa de seringueira}

Para permitir a comparação entre o $\mathrm{HCN}$-p de folhas no estádio $\mathrm{C}$ com o de folhas maduras, os dados da Tabela 4 e Figura 8 estão expressos com base na massa de folhas frescas.

Tabela 4. Potencial cianogênico ( $\mathrm{HCN}-\mathrm{p}$ ) em $\mathrm{mg} \mathrm{CN}^{-} \mathrm{g}^{-1}$ de matéria fresca, de folhas novas e maduras de clones de copa de seringueira, compatíveis e incompativeis com o clone de painel IPA 1.

\begin{tabular}{|c|c|c|c|c|c|}
\hline \multirow{2}{*}{$\begin{array}{l}\text { Clones de } \\
\text { Seringueira }\end{array}$} & \multicolumn{5}{|c|}{$\mathrm{HCN}-\mathrm{p}\left(\mathrm{mg} \mathrm{CN}^{-1} \mathrm{~g}^{-1}\right.$ matéria fresca) } \\
\hline & \multicolumn{2}{|l|}{ Folha nova } & \multicolumn{3}{|c|}{ Folha madura } \\
\hline \multicolumn{6}{|c|}{ Clones de copa incompatível } \\
\hline CNS G 124 & 0,39699 abc & A & 0,02097 & $\mathrm{c}$ & $\mathrm{B}$ \\
\hline CPAA C 06 & $0,43038 \mathrm{ab}$ & A & 0,03015 & $\mathrm{c}$ & $\mathrm{B}$ \\
\hline CBA 1 & 0,32917 bcd & $\mathrm{A}$ & 0,01915 & $\mathrm{c}$ & $\mathrm{B}$ \\
\hline CPAA C 50 & 0,23214 & A & 0,02217 & c & $\mathrm{B}$ \\
\hline CPAA C 14 & 0,20919 & $\mathrm{~A}$ & 0,01289 & $\mathrm{c}$ & B \\
\hline CPAA C 13 & 0,15389 & A & 0,01315 & $c$ & $\mathrm{~B}$ \\
\hline \multicolumn{6}{|c|}{ Clones de copa compatível } \\
\hline Fx 985 & $0,47941 \mathrm{ab}$ & A & 0,41577 & $a b$ & A \\
\hline IAN 6158 & 0,30830 bcde & A & 0,26344 & $\mathrm{~b}$ & A \\
\hline CPAA C 65 & 0,02895 & $\mathrm{~A}$ & 0,02128 & $c$ & A \\
\hline \multicolumn{6}{|l|}{ Clone de painel } \\
\hline IPA 1 & 0,54201 a & A & 0,55349 & a & A \\
\hline
\end{tabular}

Médias seguidas de mesma letra maiúscula na linha e minúscula na coluna não diferem entre si pelo teste de Tukey, ao nivel de $1 \%$ de probabilidade.

Quando calculados com base na massa das amostras secas, em se tratando de folhas jovens, os valores situam-se na faixa de 0,17 a $3,53 \mathrm{mg} \mathrm{CN}^{-} \mathrm{g}^{-1}$ de folha seca, enquanto os valores apresentados por Lieberei (1988) estão nas faixas de 
aproximadamente 1 a $5 \mathrm{mg} \mathrm{CN}^{-} \mathrm{g}^{-1}$ de folha seca, nos clones de HCN-p baixo; de 5 a 10 mg CN $\mathrm{g}^{-1}$ de folha seca, nos clones de $\mathrm{HCN}-\mathrm{p}$ médio e de 10 a $15 \mathrm{mg} \mathrm{CN}^{-1} \mathrm{~g}^{-1}$ de folha seca nos clones de HCN-p de alto, o que corresponde de 20 a $30 \%$ dos teores de nitrogênio considerados altos na análise foliar de seringueira (Shorrocks, 1964).

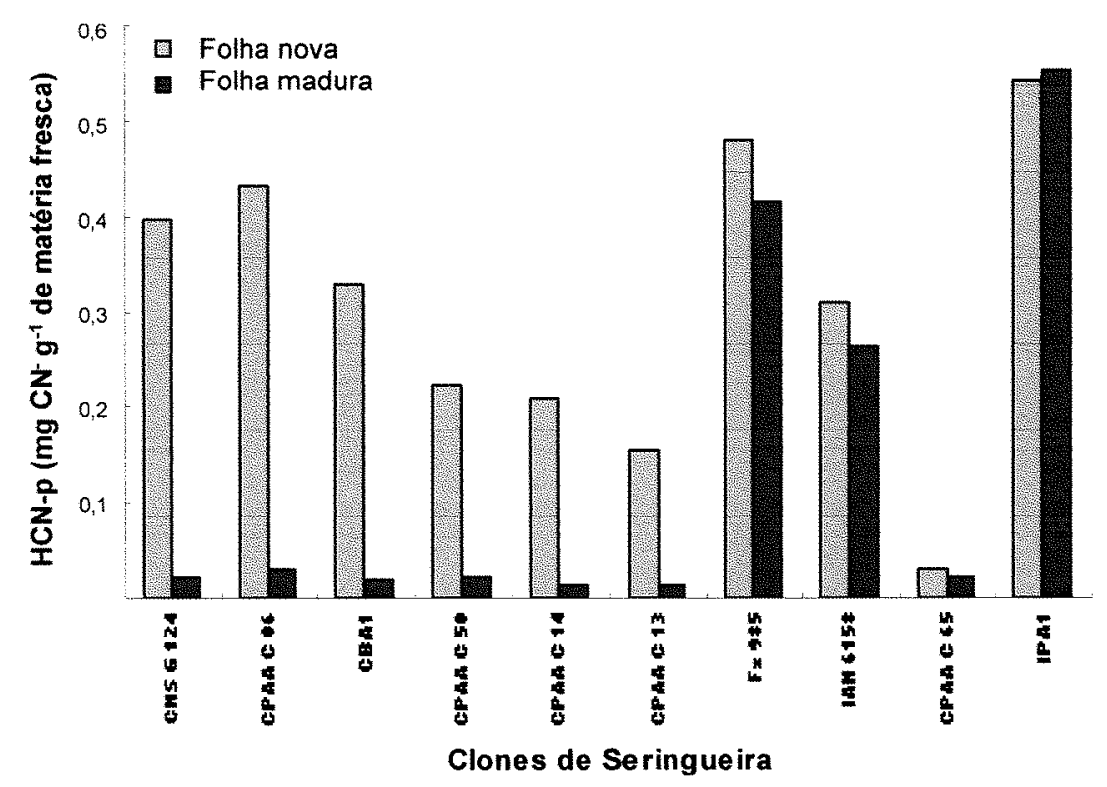

Figura 8. Potencial cianogênico ( $\mathrm{HCN}-\mathrm{p}$ ) em $\mathrm{mg} \mathrm{CN}^{-} \mathrm{g}^{-1}$ de matéria fresca, de folhas novas e maduras de clones de copa de seringueira, compatíveis e incompativeis com o clone de painel IPA 1.

Em outras espécies cianogênicas, Miller \& Conn (1980) encontraram valores de HCN-p próximos aos da Tabela 4 e Figura 8: $0,765 \mathrm{mg}$ de HCN por grama de folhas frescas de Phaseolus linatus, $0,996 \mathrm{mg}$ de $\mathrm{HCN}$ por grama da parte aérea fresca de plântulas de Sorghum bicolor e 0,552 mg de HCN grama da parte aérea de plântulas de Linum usitatissimum.

Cooke (1978), estudando cianogênese em mandioca, observou, nas duas cultivares com conteúdos mais elevados de cianeto, os valores de 0,137 e $0,97 \mathrm{mg}$ de $\mathrm{CN}^{-}$por grama de matéria fresca da epiderme e de 0,097 e $0,009 \mathrm{mg} \mathrm{CN}^{-} \mathrm{g}^{-1}$ de matéria fresca do tubérculo. 
As diferenças entre os dados da Tabela 4 e Figura 8 e os valores de HCN-p encontrados por Lieberei (1988) são dificeis de explicar, tendo-se em conta que a atividade de $\beta$-glicosidase utilizada neste trabalho foi praticamente a mesma da enzima semi purificada em coluna de Sephadex G 150 por Lieberei (1986), cerca de 0,2 $\mu \mathrm{mol}$ pNP $\min ^{-1}$ e que no teste com linamarina houve hidrólise completa, com concentração de linamarina no meio de incubação correspondendo ao $\mathrm{HCN}-\mathrm{p}$ mais alto relatado por Lieberei (1988).

Por outro lado, para efeito de classificação como de baixo, médio ou alto HCN-p, os dados de Lieberei conduzem aos mesmos resultados deste trabalho, no que se refere à classificação entre clones compatíveis e incompatíveis com o IPA 1, visto que os clones F 4512, PL 22, PUA 5 e PUA 9, de baixo HCN-p, de acordo com Lieberei (1988), mostraram-se compatíveis com o IPA 1. Além disso o clone CPAA C 65 mostrou baixo HCN-p, como era de se esperar, uma vez que é proveniente de $H$. nitida espécie definida por Lieberei (1988) como de baixo $\mathrm{HCN}$-p, embora com valores inferiores aos apresentados por esse autor.

Quando a determinação do HCN-p foi efetuada em folhas maduras, os clones incompativeis apresentaram maior uniformidade de valores, que não diferiram entre clones ao nível de $1 \%$ de probabilidade. O mesmo não foi observado nos clones compatíveis, permanecendo grande variação entre clones (Tabela 4 e Figura 8).

Quando comparados os resultados obtidos de folhas jovens com os de folhas maduras, para um mesmo clone, observa-se que, com os clones incompatíveis, ocorre uma significativa redução do $\mathrm{HCN}-\mathrm{p}$ nas folhas maduras. No entanto a mesma comparação quando realizada com os clones compatíveis, com HCN-p alto, revela que não há diferença significativa entre os valores observados nas folhas jovens e maduras de um mesmo clone (Tabela 4 e Figura 7). Por outro lado, entre os clones de HCN-p baixo, F 4512, PL 22, PUA 5 e PUA 9, de acordo com Lieberei (1988) e CPAA C 65, de acordo com a Tabela 4 , não foram encontrados clones incompatíveis.

Tal fato sugere que nos clones incompativeis há translocação das folhas maduras, provavelmente de linustatina. A deteç̧ão de linustatina no exsudado dos nectários da base do pecíolo (Selmar, 1993), dá suporte a essa inferência. 
Esses resultados indicam que, exceto nos clones com baixo $\mathrm{HCN}$-p, os valores determinados em folhas jovens dos clones de copa não está diretamente relacionado com a capacidade de desenvolvimento de processo de incompatibilidade com o clone de painel IPA 1, devido as variações de HCN-p entre foliolos jovens e maduros, indicando que nos clones incompativeis ocorre translocação de glicosídeo cianogênico das folhas maduras, não ocorrendo essa translocação nos clones compatíveis com HCN-p alto, faltando apenas a demonstração experimental do transporte de linustatina a partir das folhas, que já conta com a evidência de sua presença no exsudado dos nectários da base do pecíolo (Selmar, 1993) e a comprovação de sua translocação ao longo do caule.

A constatação de que o próprio IPA 1 tem $\mathrm{HCN}$-p alto nos folíolos jovens $(0,54$ $\mathrm{mg} \mathrm{CN} \mathrm{g}^{-1}$ de folha fresca), mantendo valor equivalente nas folhas maduras, mostra que a incompatibilidade é determinada, em essência, pela translocação ou não do glicosídeo cianogênico das folhas, do contrário o clone IPA 1 seria uma impossibilidade biológica.

As evidências apresentadas com os testes de aplicação de $\mathrm{KCN}$ e linamarina, o estudo das enzimas envolvidas e do potencial cianogênico dos clones de copa e inclusive do IPA 1 apontam de forma convergente para a hipótese do efeito da cianogênese na determinação de incompatibilidade verificada com certos clones de copa enxertados sobre o IPA 1. A Figura 9 representa um esquema dos testes aplicados com os principais objetivos e resultados para melhor compreensão do trabalho.

Os resultados obtidos neste trabalho apontam, além disso, para um fato de alcance bem maior, quando se constata a semelhança dos sintomas de incompatibilidade e os do secamento do painel de sangria (TPD) (Faÿ \& Hébant, 1980). A possibilidade do envolvimento da cianogênese na indução da TPD torna-se mais plausível, considerandose o alto HCN-p em folíolos de CNS G 124, com grande redução nos folíolos maduros, e ainda que esse clone provocou incidência muito alta de secamento de painel com copa enxertada sobre painel Fx 4098, logo nos primeiros meses de sangria (Moraes \& Moraes, 1999 ). Os resultados expõem também aspectos novos de interesse no estudo do secamento do painel, com referência ao papel das enzimas estudadas neste trabalho e sua relação com a cianogênese na casca do caule. 


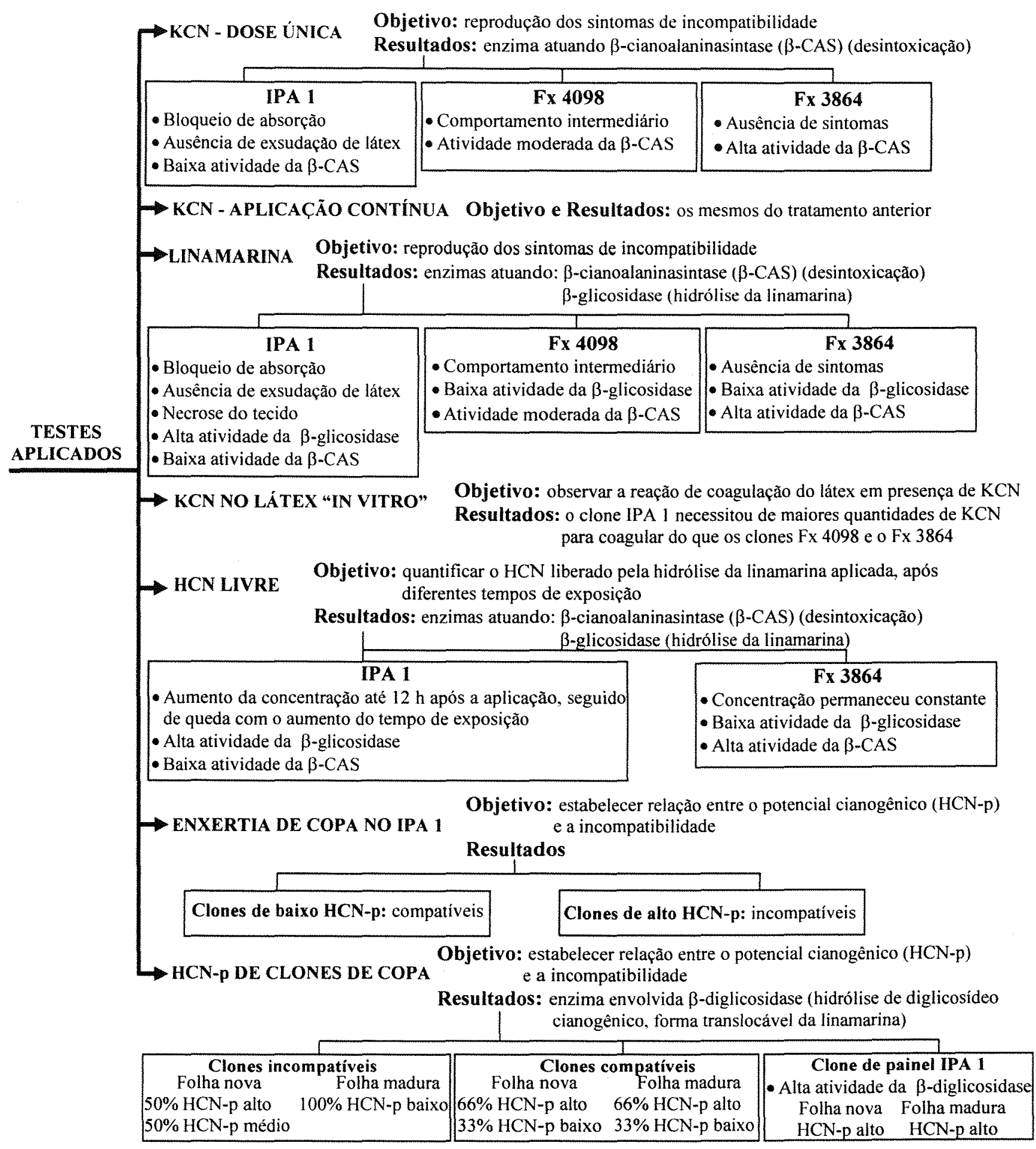

Figura 9. Esquema dos testes realizados neste trabalho com os principais objetivos e resultados. 


\section{CONCLUSÕES}

1. A incompatibilidade por translocação em enxertos de copa dos clones mencionados neste trabalho, sobre o clone IPA 1, é devida à translocação de glicosídeo cianogênico das folhas dos clones de copa, para o caule do IPA 1.

2. O clone IPA 1 apresenta atividade mais alta de $\beta$-glicosidase, capaz de hidrolizar os glicosídeos cianogênicos linamarina e lotaustralina, e de $\beta$-diglicosidase, capaz de hidrolizar a linustatina, que é a forma normal de transporte do glicosídeo, protegida da ação da $\beta$-glicosidase.

3. Os clones de baixo potencial cianogênico (HCN-p) ou de alto HCN-p, nas folhas jovens, mas que não sofrem redução do HCN-p nas folhas maduras, são compatíveis, sendo este o caso encontrado nas próprias folhas do IPA 1.

4. Os clones de HCN-p alto nas folhas jovens, com forte redução nas folhas maduras são incompatíveis.

5. A expressão de incompatibilidade das copas, com o IPA 1, está associada a uma atividade muito baixa de $\beta$-cianoalaninasintase na casca do caule.

6. A atividade muito alta de $\beta$-cianoalaninasintase na casca do Fx 3864 protege esse clone dos efeitos da cianogênese, impedindo o acúmulo de HCN livre. Essa característica encontra-se em menor grau no Fx 4098. 


\section{REFERÊNCIAS BIBLIOGRÁFICAS}

BAHIA, D.B.; SENA GOMES, A.R. Painel versus copa em alguns clones de seringueira (Hevea spp). Revista Theobroma, v.11, n.3, p.203-208, 1981.

BALDWIN JR., J.T. Hevea: a first interpretation. The Journal of Heredity, v.38, n.1, p.54-64, Jan. 1947.

BLUMENTHAL, S.G.; HENDRICKSON, H.R.; ABROL, Y.P.; CONN, E.E. Cyanide metabolism in higher plants. III. The biosynthesis of $\beta$-cyanoalanine. Journal of Biological Chemistry, v.243, n.20, p.5302-5307, Oct. 1968.

BOUGH, W.A.; GANDER, J.E. Exogenous L-tyrosine metabolism and dhurrin turnover in sorghum seedlings. Phytochemistry, v.10, n.1, p.67-77, 1971.

CASTRIC, P.A.; FARNDEN, K.J.F.; CONN, E.E. Cyanide metabolism in higher plants. V. The formation of asparagine from $\beta$-cyanoalanine. Archives of Biochemistry and Biophysics, v.152, p.62-69, 1972.

CHEW, M.Y. Rhodanese in higher plants. Phytochemistry, v.12, n.10, p.2365-2367, Oct. 1973.

CLEGG, D.O;; CONN, E.E.; JANZEN, D.H. Developmental fate of the cyanogenic glucoside linamarin in Costa Rican wild lima bean seeds. Nature, v.278, n.5702, p.343-344, Mar. 1979.

CONN, E.E. Cyanogenic compounds. Annual Review of Plant Physiology, v.31, p.433-451, 1980. 
COOKE. R.D. An enzymatic assay for the total cyanide content of cassava (Manihot esculenta Crantz). Journal of the Science of Food and Agriculture, v.29, n.4, p.345-352, Apr. 1978.

D'AUZAC, J.; JACOB, J.L.; CHRESTIN, H. Physiology of rubber tree latex. Boca Raton. CRC Press, 1989. 470p.

DIJKMAN, M.J. Hevea - Thirty years of research in the far east. Coral Gables: University of Miami Press. 1957. 329p.

DUNHAM, R.J.; SILVA, E.R.; SANTOS, A.G. Relatório preliminar sobre o desenvolvimento de enxerto de copa de Hevea brasiliensis na Fazenda Três Pancadas, Firestone, Bahia. IN: SEMINÁRIO SOBRE ENXERTIA DE COPA DA SERINGUEIRA, 1., Brasília, 1982. Anais. Brasília: SUDHEVEA, 1982. p.92134.

FAŸ, E.; HÉBANT, C. Étude histologique des écorces d'Hevea brasiliensis atteint de la maladie des encoches sèches. Compte Rendu a l'Academie de Sciences de Paris. Serie D. Sciences Naturales, v.291, n.10, p.865-868, 1980.

FEUCHT, W. Graft incompatibility of tree crops: na overview of the present scientific status. In: INTERNATIONAL SYMPOSIUM ON VEGETATIVE PROPAGATION OF WOOD SPECIES. Acta Horticulturae, n.277, p.33-41, 1988.

FLOSS, H.G.; HADWIGER, L.; CONN, E.E. Enzymatic formation of $\beta$-cyanoalanine from cyanide. Nature, v.208, n.5016, p.1207-1208, Dec. 1965.

GOUDEY, J.S.; TITLLE, F.R.; SPENCER, M.S. A role for ethylene in the metabolism of cyanide by higher plant. Plant Physiology, v.74, n.4, p.1306-1310, 1989. 
GRUHNERT, C.; BIEHL, B.; SELMAR, D. Compartmentation of cyanogenic glucosides and their degrading enzymes. Planta, v.195, n.1, p.36-42, 1994.

GUR, A. The incompatibility of the pear with quince rootstock. Israel Ministry of Agriculture Research Station, 1957. 36p. (Special Bulletin, 10)

HAHLBROCK, K.; CONN, E.E. Evidence for the formation of linamarin and lotaustralin in flax seedlings by the same glucosyltransferase. Phytochemistry, v.10, p.1019-1023, 1971.

HARTMANN, T.H.; KESTER, D.E.; DAVIES JR, F.T. Plant propagation: principles and practices. 5 ed. New Jersey: Englewood Cliff, 1990. 647p.

HERRERO, J. Studies of compatible and incompatible graft combinations with special reference to hard fruit trees. Journal of Fruticultural Science, v.26, n.1, p.168$237,1951$.

KAKES, P. Properties and functions of the cyanogenic system in higher plants. Euphytica, v.48, n.1, p.25-43, June. 1990.

LANGFORD, M.H. The status of Hevea rubber planting material for use in tropical America. Turrialba, v.7, n.4, p.104-11, Oct/Dec. 1957.

LASSCHNIT, J.A.; VOLLEMA, J.S. The meadow-resistant clone LCB 870. Bergcultures, v.21, p.257-261, 1952.

LIEBEREI, R. Cyanogenesis of Hevea brasiliensis during infection with Mycrocyclus ulei. Journal of Phytopathology, v.115, n.2, p.134-146, Feb. 1986. 
LIEBEREI, R. Relationship of cyanogenic capacity (HCN-c) of the rubber tree Hevea brasiliensis to susceptibility to Microcyclus ulei, the agent causing South American leaf blight. Journal of Phytopathology, v.122, n.1, p.54-67, May. 1988.

LIEBEREI, R.; BIEHL, B.; GIESEMANN, A.; JUNQUEIRA, N.T.V. Cyanogenesis inhibits active defense reactions in plants. Plant Physiology, v.90, p.33-36, 1998.

LIEBEREI, R.; NAHRSTEDT, A.; SELMAR, D.; GASPAROTTO, L. Occurrence of lotaustralin in the genus Hevea and changes of $\mathrm{HCN}$-potencial in developing organs of Hevea brasiliensis. Phytochemistry, v.25, n.7, p.1573-1578, 1986.

MALLIKA, G.V.; JANS, E.R.; PIERIS, M.N.; ABEYESEKARA, A.M. The cyanogênic glucosides and glucosidases of rubber seed kernels. Journal of the National Science Council of Sri Lanka, v.19, n.2, p.99-106, 1991.

MARCINOWSKI, S.; FALK, H.; HAMMER, D.K.; HOYER, B.; GRISEBACH, H. Appearence and localization of a $\beta$-glucosidase hydrolyzing conifer in spruce (Picea abies). Planta, v.144, p.161-165, 1979.

McILVAINE, T.C. A buffer solution for colorimetric comparison. Journal of Biological Chemistry, v.49, p.183-186, 1921.

MILLER, J.M.; CONN, E.E. Metabolism of hydrogen cyanide by higher plants. Plant Physiology, v.65, n.6, p.1199-1202, June. 1980.

MORAES, V.H.F. Enxertia de copa para remoçã dos impedimentos naturais a heveicultura na Amazônia sempre úmida. Subprojeto (070.94.018.01). Manaus: Embrapa Amazônia Ocidental, 1999. 12p. (EMBRAPA. Programa (07) - Sistema de Produção de Matérias Primas). Relatório Final. 
MORAES, V.H.F. Sumário das pesquisas sobre enxertia de copa da seringueira no CPAA. Manaus: Embrapa-CPAA, 1997. 25p. (Embrapa-CPAA. Documentos, 8).

MORAES, V.H.F.; MORAES, L.A.C. Diagnóstico do látex em sangria precoce de seringueira com copas enxertadas. Possibilidade de emprego na seleção precoce de clones de copa e de painel. Agrotópica, v.7, n.3, p.49-62, 1995.

MORAES, V.H.F.; MORAES, L.A.C. Secamento do painel de sangria do clone de seringueira Fx 4098 (Hevea brasiliensis) sob copa enxertada de $H$. pauciflora. Correlação com teores de magnésio no látex e resposta a dose suplementar de magnésio. Manaus: Embrapa Amazônia Ocidental, 1999. 6p. (Embrapa Amazônia Ocidental. Comunicado Técnico 3).

MORAES, W.H.F.; MORAES, L.A.C. Seleção precoce de clones de copa e de painel de seringueira para experimentos de avaliação de clones com copas enxertadas. Agrotrópica, v.8, n.1, p.23-26, 1996.

MORITA, T.; ASSUMPÇÃO, R.M.V. Manual de soluções, reagentes \& solventes. 2.ed. São Paulo: Editora Edgar Blücher Ltda, 1990. 627p.

MOSSE, B. Graft-incompatibility in fruit trees. East Mailing Bureau of Horticulture. 1962. 36p. (Technical Communication, 28).

OSTENDORF, F.W. Twe proeven met neervondigne Hevea oculaties. Archief von de Rubbercultuur, v.26, p.27-43, 1949.

PEISER, G.D.; WANG, T.T.; HOFFMAN, N.E.; YANG, S.F.; LIU, H.W.; WALSH, C.T. Formation of cyanide from carbon 1 of 1-aminocyclopropane-1-carboxylic acid during its conversion to ethylene. Proceedings of the National Academy of Sciences of the United States of America, v.81, n.10, p.3059-3063, May. 1984. 
PINHEIRO, E. A heveicultura nas "áreas de escape" do Brasil. Manaus: In: WORKSHOP. ASSOCIATION OF NATURAL RUBBER PRODUCING COUNTRIES, 3., Manaus, 1997. Palestras. Manaus: SALB, 1997. 21p.

PINHEIRO, E.; LIBERRATI, V.F.; CASTRO, C.; PINHEIRO, F.S.V. A enxertia de copa na formação de seringais de cultivo nos trópicos úmidos da Amazônia. Belém: FCAP. 1988. 27p. (Informe Técnico, 13).

PINHEIRO, E.; LIBONATI, V.F.; CASTRO, C.; PINHEIRO, F.S.V. A enxertia de copa na formação de seringais de cultivo nos trópicos úmdos da Amazônia. In: SEMINÁRIO SOBRE ENXERTIA DE COPA DA SERINGUEIRA, 1989, Manaus. Anais. Brasilia: EMBRAPA/SUDHEVEA, p.63-81. 1989.

RADJINO, A.J. Effect of Oidium and Dothidella resitent crowns on growth and yield of Hevea brasiliensis. Jounal of Rubber Research Institute of Malaya, v.21, n.1, p.56-63, 1969.

RUBBER RESEARCH INSTITUTE OF INDIA. Crown budding of susceptible high yielding clones with resistant/tolerant clones. In: RUBBER RESEARCH INSTITUTE OF INDIA. Annual Report 1986/87. Kerala, 1987. - -.37-38.

SCOTT, W.W. Standard methods of chemical analysis, v.2, 5.ed. New York: D. van Nostand Co., 1939. 2617p.

SEIBERT, R.J. A study of Hevea (with its economic aspects) in the Republic of Peru. Annals of the Missouri Botanical Garden, v.34, p.261-353, 1947.

SELMAR, D. Cyanogenic glucosides - constituents of xylem and phoem sap? Plant Physiology, v.89, n.4 (Supplement), p.193, Apr. 1989. 
SELMAR, D. Transport of cyanogenic glucosides linustatin uptake by Hevea cotyledons. Planta, v.191, p.191-198, 1993.

SELMAR, D. Cyanogenese in.Hevea. Zwei wege zur metabolisierung cyanogener glucoside. Braunschweig, 1986. 171p. Tese (Doutorado) - Technischey Universität Braunschweig.

SELMAR, D.; LIEBEREI, R.; BIEHL, B. Mobilization and utilization of cyanogenic glycosides. Plant Physiology, v.86, p.711-716, 1988.

SELMAR, D.; LIEBEREI, R.; BIEHL, B.; CONN, E.E. $\alpha$-hydroxinitrile lyase in Hevea brasiliensis and its significance for rapid cyanogenesis. Physiologia Plantarum, v.75, n.97-101, 1989.

SELMAR, D.; GROCHOLEWSKI, S.; SEIGLER, D.S. Cyanogenic lipids: Utilization during seedling development of Ungnadia speciosa. Plant Physiology, v.93, n.2, p.631-636, June. 1990 .

SELMAR, D.; LIEBEREI, R.; BIEHL, B.; NAHRSTEDT, A.; SCHMIDTMANN, V.; WRAY, V. Occurence of the cyanogen linustatin in Hevea brasiliensis. Phytochemistry, v.26, n.8, p.2400-2401, 1987.

SELMAR, D.; LIEBEREI, R.; BIEHL, B.; VOIGT, J. Hevea linamarase-A nonspecific $\beta$-glycosidase. Plant Physiology, v.83, n.3, p.557-563, 1987.

SELMAR, D.; LIEBEREI, R.; JUNQUEIRA, N.; BIHEL, B. Changes in cyanogenic glucoside conten in seeds and seedlings of Hevea species. Phytochemistry, v.30, n.7, p.2135-2140, 1991. 
SHORROCKS, V.M. Mineral deficiencies in Hevea and associated cover crops. Rubber Research Institute. Kuala Lumpur. Malaysia. 76p.

SIEW, F.; SHAOQIONG, Y. Preliminary study of cyanide resistant respiration in Hevea brasiliensis, In COLLOQUE EXPLOTATION PHYISIOLOGIE ET AMÉLIORATION DE L'HEVEA. Montpellier, 1984. Compte-Rendu. Montpellier. IRCA/GERDAT, 1984. p.185-203.

TAN, H.; LEONG, W. Crown budding results of a survey of states in Northen peninsular Malaya. In: PLANTER'S CONFERENCE, 1977, Kuala Lumpur. Proceedings. Kuala Lumpur: RRIM, 1977. p.45-57.

UMBACH, H. $\beta$-cyanoalanin synthase in Hevea species. Braunschweig, 1989. 76p. Tese (Graduação) - Technischey Universität Braunschweig.

YOON, P.K. Further progress in crown budding. In: PLANTER'S CONFERENCE, 1971. Kuala Lumpur. Proceedings. Kuala Lumpur: RRIM, 1972. p.143-153. 